\title{
Siberian fire smoke in the High-Arctic winter stratosphere observed during MOSAiC 2019-2020
}

Kevin Ohneiser ${ }^{1}$, Albert Ansmann ${ }^{1}$, Ronny Engelmann ${ }^{1}$, Christoph Ritter $^{2}$, Alexandra Chudnovsky ${ }^{3}$, Igor Veselovskii ${ }^{4}$, Holger Baars ${ }^{1}$, Henriette Gebauer ${ }^{1}$, Hannes Griesche ${ }^{1}$, Martin Radenz ${ }^{1}$, Julian Hofer ${ }^{1}$, Dietrich Althausen ${ }^{1}$, Sandro Dahlke ${ }^{2}$, and Marion Maturilli ${ }^{2}$

${ }^{1}$ Leibniz Institute for Tropospheric Research, Leipzig, Germany

${ }^{2}$ Alfred Wegener Institute, Helmholtz Centre for Polar and Marine Research, Potsdam, Germany

${ }^{3}$ Tel Aviv University, Porter School of Earth Sciences and Environment, Tel Aviv, Israel

${ }^{4}$ Prokhorov General Physics Institute of the Russian Academy of Sciences, Moscow, Russia

Correspondence: K. Ohneiser

(ohneiser@ tropos.de)

\section{Abstract.}

During the one-year MOSAiC (Multidisciplinary drifting Observatory for the Study of Arctic Climate) expedition the German icebreaker Polarstern drifted through the Arctic Ocean ice from October 2019 to May 2020, mainly at latitudes between $85^{\circ} \mathrm{N}$ and $88.5^{\circ} \mathrm{N}$. A multiwavelength polarization Raman lidar was operated aboard the research vessel and continuously monitored aerosol and cloud layers up to $30 \mathrm{~km}$ height. The highlight of the lidar measurements was the detection of a persistent, $10 \mathrm{~km}$ deep wildfire smoke layer in the upper troposphere and lower stratosphere (UTLS) from about 7-8 km to 17-18 km height. The smoke layer was present throughout the winter half year until the polar vortex, the strongest of the last 40 years, collapsed in late April 2020. The smoke originated from major fire events, especially from extraordinarily intense and long-lasting Siberian fires in July and August 2019. In this article, we summarize the main findings of our seven-month smoke observations and characterize the aerosol properties and decay of the stratospheric perturbation in terms of geometrical, optical, and microphysical properties. The UTLS aerosol optical thickness (AOT) at $532 \mathrm{~nm}$ ranged from 0.05-0.12 in October-November 2019 and was of the order of 0.03-0.06 during the central winter months (December-February). As an unambiguous sign of the dominance of smoke, the particle extinction-to-backscatter ratio (lidar ratio) at $355 \mathrm{~nm}$ was found to be much lower than the respective $532 \mathrm{~nm}$ lidar ratio. Mean values were $55 \mathrm{sr}(355 \mathrm{~nm})$ and $85 \mathrm{sr}(532 \mathrm{~nm})$. We further present a review of previous heightresolved Arctic aerosol observations (remote sensing) in our study. For the first time, a coherent and representative view on the aerosol layering features in the Central Arctic from the surface up to $27 \mathrm{~km}$ height during the winter half year is presented. Finally, a potential impact of the wildfire smoke aerosol on the record-breaking ozone depletion over the Arctic in the spring of 2020 is discussed based on smoke, ozone, and polar stratospheric cloud observations.

\section{Introduction}

As part of the one-year MOSAiC (Multidisciplinary drifting Observatory for the Study of Arctic Climate) expedition (MOSAiC, last access: 5 January, 2021), lasting from September 2019 to October 2020, an advanced multiwavelength polarization 
Raman lidar was operated aboard the German icebreaker Polarstern (Knust, 2017). The lidar continuously monitored aerosol and cloud layers in the Central Arctic up to $30 \mathrm{~km}$ height (Engelmann et al., 2020). MOSAiC was the largest Arctic field campaign ever conducted. The expedition was motivated by the rapid sea ice loss, the unusual Arctic warming, and our incomplete knowledge about the complex processes controlling the Arctic climate (Wendisch et al., 2017, 2019). The research vessel (RV) Polarstern served as the main MOSAiC platform for advanced remote sensing studies of the atmosphere. The ice breaker was trapped in the ice from October 2019 to May 2020 and drifted through the Arctic Ocean at latitudes mainly between $85^{\circ} \mathrm{N}$ and $88.5^{\circ} \mathrm{N}$.

The occurrence of a persistent wildfire smoke layer in the upper troposphere and lower stratosphere (UTLS) from 7-8 km to $17-18 \mathrm{~km}$ height over the entire winter half year 2019-2020 is one of the unprecedented events observed during the MOSAiC expedition (Engelmann et al., 2020). The smoke layer began to dissolve in late April 2020, when the extraordinarily strong polar vortex, the strongest of the last 40 years (Lawrence et al., 2020), collapsed. Here, we present the results of the MOSAiC UTLS smoke observations in all details. Based on the continuous lidar observations we describe the development of the smoke conditions, the aerosol vertical layering, optical, and microphysical properties over the seven-month period. We discuss the slow decay of the stratospheric perturbation with time and compare our findings with previous and ongoing long-term aerosol observations conducted with ground-based and spaceborne lidars and by means of passive remote sensing.

Favorable conditions for a strong perturbation of the stratospheric aerosol conditions at high northern latitudes were given in 2019. Record-breaking temperatures in the Arctic (Yadav et al., 2020; NOAA, last access: 5 January, 2021) caused a large number of intense fires in the summer of 2019 (FIRMS, last access: 5 January, 2021). The burning season 2019 was the most disastrous fire period on record within the Arctic circle (CAMS-1, last access: 5 January, 2021; Bob Berwyn, Inside Climate News, last access: 5 January, 2021). From 19 July to 14 August 2019, rather intense and long-lasting forest fires occurred in central and eastern Siberia between $55^{\circ}$ and $70^{\circ} \mathrm{N}$ and injected enormous amounts of wildfire smoke into the free troposphere, in closest neighborhood to the Central Arctic. Figure 1 visualizes the tremendous environmental disaster over the eastern part of Siberia end of July 2019. Several large fire centers are visible located north, northwest and northeast of Lake Baikal $\left(53.5^{\circ} \mathrm{N}\right.$, $108^{\circ} \mathrm{E}$ ). Figure 2 provides a quantitative overview of the smoke situation based on a map of the monthly mean aerosol optical thickness (AOT) for the time period from 20 July to 20 August 2019. The heaviest fires occurred in the region indicated by box 1 (about $650 \mathrm{~km}$ x $750 \mathrm{~km}$ ) in Fig. 2, located directly north of Lake Baikal. Monthly mean AOT values frequently exceeded 1.5, and over some regions even 2.0. All white and colored pixels indicate areas with monthly mean AOT $>1$. The day-by-day time series of the area-mean $550 \mathrm{~nm}$ AOT for the main fire centers in Fig. 2 shows that the AOT (in box 1) ranged from 1-2.5 over a seven-day period (in July 2019) and was continuously $>1$ for more than 8 days in August 2019.

At these high AOT levels, it is very likely that the smoke ascended up to the tropopause height within a couple of days as a result of absorption of shortwave solar radiation and heating of the smoke layers. Buoyancy is created and triggers self-lifting over several kilometers (Boers et al., 2010; de Laat et al., 2012). Such self-lifting processes were observed several times in recent years after major wildfire events (Khaykin et al., 2018, 2020; Torres et al., 2020; Ohneiser et al., 2020; Kablick et al., 2020). Our simulations reveal that smoke layers with a typical black carbon fraction of 5\% and particle extinction coefficients of 500-2000 $\mathrm{Mm}^{-1}$ at $550 \mathrm{~nm}$ need about 3-10 days to ascend from 3-5 km height (smoke injection height) to the tropopause 
(around $11 \mathrm{~km}$ ). After reaching the tropopause, the smoke obviously spread over the entire UTLS height regime by vertical mixing and further ascent during the following weeks and months. The CALIPSO (Cloud-Aerosol Lidar and Infrared Pathfinder Satellite Observation) lidar observations in Fig. 3 corroborate our hypothesis. Smoke layers were observed over the main fire areas $\left(55^{\circ}-68^{\circ} \mathrm{N}, 85^{\circ}-95^{\circ} \mathrm{E}\right)$ up to the tropopause on 26 July 2019 . Traces of smoke are visible at heights between 10 and $15 \mathrm{~km}$ as well. The stratospheric smoke layers were dispersed over large parts of the high northern latitudes and covered the entire Artic region in September and October 2019. These layers were even seen by ground-based lidars in Finland and Germany in August 2019 (PollyNet, last access: 5 January, 2021). The aerosol over the Central Arctic was then trapped within the strong polar vortex and remained detectable over the North Pole region during the first half of the MOSAiC expedition until mid of spring of 2020 .

Aerosol conditions over the Central Arctic were complex in the winter halfyear of 2019-2020. Besides the Siberian fires, the Raikoke volcano in the Kuril Islands $\left(48.3^{\circ} \mathrm{N}, 153.3^{\circ} \mathrm{E}\right)$ erupted on 22 June 2019 and influenced the aerosol conditions in the lower stratosphere at all latitudes north of $50^{\circ} \mathrm{N}$ (Kloss et al., 2021; Vaughan et al., 2020). The volcanic $\mathrm{SO}_{2}$ plumes were converted to sulfuric-acid-containing water droplets (about $75 \% \mathrm{H}_{2} \mathrm{SO}_{4}$ and $25 \% \mathrm{H}_{2} \mathrm{O}$ ) in the following weeks. The bluish stratospheric layers between $13-17 \mathrm{~km}$ height at $45^{\circ}-60^{\circ} \mathrm{N}$ in Fig. 3 may indicate Raikoke-related volcanic aerosol. Furthermore, several smoke injections into the stratosphere caused by pyrocumulonimbus (pyroCb) convection (Fromm et al., 2010) occurred, e.g., in western North America on 16-20 June 2019.

Importantly, in addition to the strong stratospheric aerosol perturbation, a record-breaking ozone depletion was observed over the Arctic in the spring of 2020 (DeLand et al., 2020; Manney et al., 2020; Wohltmann et al., 2020; Inness et al., 2020; Wilka et al., 2021; Dameris et al., 2021; Smyshlyaev et al., 2021). A potential impact of stratospheric aerosol on the complex chemical processes leading to this strong ozone reduction was however not mentioned in any of these articles. As the main reason for the extraordinary large ozone depletion, the long-lasting, rather cold polar vortex was identified. The vortex triggered the development of polar stratospheric clouds over a comparably long time period from January to April 2020, strong chlorine activation, and ozone destruction. However, to what extent the polar smoke layers influenced ozone depletion in the spring of 2020 remain an open question that need to be clarified in the course of the MOSAiC data analysis and future studies on the interplay between smoke, polar stratospheric clouds (PSCs), and ozone depletion.

The article is organized as follows. A brief description of the Polarstern lidar and the data analysis is given in Sect. 2. Then, we present our MOSAiC smoke observations in Sect. 3. We begin with October and November 2019 case studies in Sect. 3.1 , and continue with an overview of all lidar observations from October 2019 to May 2020 in Sect. 3.2. In this context, we will also discuss the potential contribution of Raikoke volcanic aerosol particles to the observed aerosol optical and microphyscial properties. In Sect. 3.3, we compare our results with foregoing field studies and long-term observations of optical properties to highlight again the strong perturbation found in the MOSAiC winter half year of 2019-2020. Finally, in Sect. 4, we illuminate to what extent the spread of wildfire smoke particles as well as the occurrence of PSCs, as observed with the CALIPSO and MOSAiC lidars, may have contributed to the stratospheric ozone depletion over the high Arctic. A summary and concluding remarks are given in Sect. 5. 


\section{MOSAiC lidar data analysis}

During the one-year MOSAiC expedition the multiwavelength polarization Raman lidar Polly (POrtabLe Lidar sYstem) (Engelmann et al., 2016) was continuously operated aboard Polarstern. An overview of the Polarstern lidar instrument and all retrievable aerosol products is given by Engelmann et al. (2020). Continuous, automated measurements of aerosol and cloud profiles up to stratospheric heights were collected from 26 September 2019 to 2 October 2020. From the beginning of October 2019 to the beginning of April 2020, the research vessel was north of $85^{\circ} \mathrm{N}$ and reached the maximum northern latitude of $88.6^{\circ} \mathrm{N}$ on 20 February 2020 . A photograph of the Polarstern in the ice and snow-covered Arctic Ocean together with a photograph of the main ship-based MOSAiC atmospheric measurement platforms aboard Polarstern is shown in Fig. 2 in Engelmann et al. (2020). Six containers for in situ aerosol monitoring and for active remote sensing of aerosols and clouds with lidars and radars were deployed on the front deck of the research vessel including the ARM (Atmospheric Radiation Measurement) mobile facility AMF-1 (ARM, last access: 5 January, 2021).

The Polly instrument is mounted inside the OCEANET-Atmosphere container of the Leibniz Institute for Tropospheric Research (TROPOS). This container is designed for routine operation aboard Polarstern between Bremerhaven, Germany, and Cape Town, South Africa and Punta Arenas, Chile (Kanitz et al., 2011, 2013), and was operated for the first time in the Arctic during a two-month campaign in June and July 2017 (Griesche et al., 2020). The OCEANET Polly instrument belongs to the lidar network PollyNET (Baars et al., 2016) which is part of the European Aerosol Research Lidar Network (EARLINET) (Pappalardo et al., 2014) organized within the Aerosols, Clouds and Trace gases Research InfraStructure (ACTRIS) project (ACTRIS, last access: 5 January, 2021).

The setup and basic technical details of the Polly instrument are given in Engelmann et al. (2016). The Polly instrument has 13 measurement channels (polarization sensitive channels, elastic-backscatter, water vapor and nitrogen Raman channels, for near-range and far-range profiling). Laser pulses are emitted at the wavelengths of 355, 532, and $1064 \mathrm{~nm}$. Height profiles of the particle backscatter coefficient at the laser wavelengths, of the particle extinction coefficient at 355 and $532 \mathrm{~nm}$, respective extinction-to-backscatter ratio (lidar ratio) at $355 \mathrm{~nm}$ and $532 \mathrm{~nm}$, the particle linear depolarization ratio at $355 \mathrm{~nm}$ and $532 \mathrm{~nm}$ (Baars et al., 2016, 2019; Hofer et al., 2017; Haarig et al., 2018; Ohneiser et al., 2020), and the mixing ratio of water vapor to dry air by using the Raman lidar return signals of water vapor and nitrogen (Dai et al., 2018) can be determined.

Although PollyNET delivers automatically calculated profiles, the lidar observations were manually analyzed for the smoke layers. In order to accurately determine the optical properties of the smoke layers with high signal-to-noise ratio, temporal averaging over comparably long time periods of 3-18 hours were usually necessary. The basic elastic-backscatter and Raman signal profiles were vertically smoothed with a window length of $457.5 \mathrm{~m}$ (61 bins, $7.5 \mathrm{~m}$ vertical resolution) in the case of the backscatter and depolarization ratio profiles. Particle extinction and extinction-to-backscatter ratio (lidar ratio) profiling is based on a least-squares regression analysis (Baars et al., 2016). Here, we used regression window lengths of $2002.5 \mathrm{~m}$ (267 bins) in the computations. Afterwards, we further smoothed the profiles of the lidar products (backscatter, extinction, depolarization, and lidar ratios) linearly with window lengths increasing from 8 bins (at smoke layer base) to 11 bins (at layer 
top) in the case of the particle backscatter and depolarization ratio profiles, and increasing from 15 bins (base) to 20 bins (top) and from 45 bins (base) to 53 bins (top) in the case of the particle extinction and lidar ratio profiles, respectively.

Auxiliary data are required in the lidar data analysis in form of temperature and pressure profiles in order to calculate and correct for Rayleigh backscatter and extinction influences on the measured lidar return signal profiles. As an important contribution to MOSAiC, radiosondes were routinely launched every 6 hours throughout the entire MOSAiC period. In our lidar data analysis and discussion of the results, we use the preliminary radiosonde products that were directly available during the expedition.

We also checked our observations for PSC occurrence and removed the profile parts that showed PSCs from the smoke data base. These stratospheric clouds can usually be easily identified. However, weak PSC structures developed in the smoke as well, predominately in January and February 2020, and these not well-defined layers were not removed. The impact of these weak PSC layers is discussed in the next section.

Smoke microphysical properties such as volume, mass, and surface area concentration were retrieved by applying the POLIPHON (Polarization Lidar Photometer Networking) approach (Ansmann et al., 2020). A smoke particle density of $1.15 \mathrm{~g} \mathrm{~cm}^{-3}$ was assumed in the mass concentration retrieval. Alternatively to the POLIPHON method, we used the multiwavelength lidar inversion technique (Veselovskii et al., 2002) to derive microphysical properties of the smoke layers including the particle size distribution.

Additionally, we compare the Polly observations with CALIOP data (CALIOP, last access: 5 January, 2021) and also with measurements with the Spitsbergen lidar KARL (Koldewey Aerosol Raman Lidar) (KARL, last access: 5 January, 2021; Hoffmann et al., 2009; Ritter et al., 2016). The lidar is located in Ny-Ålesund (Svalbard, Norway, $78.9^{\circ} \mathrm{N}, 11.9^{\circ} \mathrm{E}$ ). In the discussion of a potential impact of the wildfire smoke on the record-breaking ozone depletion in the spring of 2020 , we use the MOSAiC ozone profiles measured with ozone sondes launched at Polarstern on a regular schedule from October 2019 to May 2020 (von der Gathen and Maturilli, 2020; Wohltmann et al., 2020).

For our studies of the smoke in the upper troposphere and lower stratosphere and quantification of the tropospheric and stratospheric smoke fractions, a good knowledge of the tropopause height is required. The tropopause was computed from the radiosonde temperature and pressure profiles by using the approach of the Global Modeling and Assimilation Office (GMAO), Goddard Space Flight Center, Greenbelt, Maryland, USA (GMAO, 2008). In this approach, the tropopause height $z_{\mathrm{TP}}$ is found from the height profile of the difference $\alpha T(z)-\log _{10} p(z)$ with $\alpha=0.03$, temperature $T$ in Kelvin, pressure $p$ in hPa, and height $z$ in meter. The tropopause pressure $p\left(z_{\mathrm{TP}}\right)$ is defined as the pressure where the defined difference reaches its first minimum above the surface. If no clear minimum was found up to $z=13000 \mathrm{~m}$ over Polarstern, a tropopause height $30 z_{\mathrm{TP}}$ was not assigned. The obtained tropopause heights agree well with the ones we obtain by applying the definition of the World Meteorological Organization (WMO, 1992) to the radiosonde temperature profiles and considering refinements in the determination described by Klehr (last access: 5 January, 2021). 


\section{Observations}

Figure 1 in Engelmann et al. (2020) shows the track of the drifting RV Polarstern from October 2019 to May 2020. The Polarstern was at latitudes $\geq 85^{\circ} \mathrm{N}$ from the beginning of October 2019 to the beginning of April 2020. The highest northern latitude with $88.6^{\circ} \mathrm{N}$ was reached around 20 February 2020. The MOSAiC expedition provided for the first time the unique opportunity to perform lidar observations close to the North Pole over the entire winter half year. This part of the Central Arctic is not covered by any other lidar measurement. The spaceborne CALIPSO lidar is blind for the region $>81.8^{\circ} \mathrm{N}$. A first brief overview of our UTLS smoke observations from October 2019 to May 2020 was given in Engelmann et al. (2020). In this section, we present the full set of observed optical and microphysical properties and summarize the main results. We begin with several case studies in Sect. 3.1. A detailed October-to-May overview is then given in Sect. 3.2. In the last subsection (Sect. 3.3), we provide a review of published Arctic aerosol profile observations, conducted since 2000, and integrate them into our measurements to provide, for the first time, a coherent view on the aerosol conditions in the Central Arctic up $26 \mathrm{~km}$ height.

\subsection{The polar UTLS smoke layer in the autumn of 2019: case studies}

Figure 4 shows the aerosol situation over the Central Arctic on 25 October 2019. The Polarstern was at $85.4^{\circ} \mathrm{N}$ and $127.9^{\circ} \mathrm{E}$ at 10:00 UTC. A haze layer with stratiform structures extended from the surface up to $4.5 \mathrm{~km}$ height and the aged smoke layer with smooth structures ranged from 5.5 to $15 \mathrm{~km}$ height as indicated by dashed lines in Fig. 4. Most of the smoke was above the tropopause, and thus above $8 \mathrm{~km}$ height. The HYSPLIT backward trajectories (HYSPLIT, last access: 5 January, 2021) in Fig. 5 for the arrival height of $10 \mathrm{~km}$ (center of the smoke layer) suggest that the polluted UTLS air mass was already trapped in the Arctic circulation system in October 2019, i.e., before the rather strong, long-lasting and cold polar vortex was fully established. According to Fig. 5, the same air mass moved twice over the location of RV Polarstern within 10 days in these late October days.

Figure 6 presents mean height profiles of the basic lidar products for the case shown in Fig. 4. Another case, measured on 7 November 2019, is shown in Fig. 7. Here, the Polarstern observations at $85.9^{\circ} \mathrm{N}$ on 7 November are compared with the AWI multiwavelength Raman lidar observations at Spitsbergen at $78.9^{\circ} \mathrm{N}$ of 4 November. Very similar smoke conditions were found over and $700 \mathrm{~km}$ south of the Polarstern. Long signal averaging times and large vertical smoothing length were necessary to reduce the impact of signal noise at these comparably clean polar conditions. Because of the necessary signal and product smoothing procedures, the true (effective) height resolution is about $500 \mathrm{~m}$ (backscatter, depolarization ratio), $2000 \mathrm{~m}$ (extinction), and $2400 \mathrm{~m}$ (lidar ratio). The KARL observations were generally smoothed with window length of $2400 \mathrm{~m}$.

As can be seen in Fig. 6 and 7, the maximum backscatter and extinction values were found around 9-10 km height, and thus just above the tropopause so that the possibility of removal of the aerosol particles by cirrus clouds (via particle scavenging and sedimentation processes) was no longer given. From the backscatter coefficient the boundaries of the smoke layer as given in Fig. 6a and 7a were determined. The maximum extinction coefficients in the center of the smoke layer were in the range of 15 to $25 \mathrm{Mm}^{-1}$ and the AOT of the UTLS polar smoke layer was of the order of 0.1 at $532 \mathrm{~nm}$ in October and early 
November 2019. The wavelength dependence of the extinction coefficient $\sigma_{\lambda}$, expressed in terms of the Ångström exponent $A_{\sigma, 355,532}=\ln \left(\sigma_{355} / \sigma_{532}\right) / \ln (532 / 355)$ with wavelengths $\lambda$ of 355 and $532 \mathrm{~nm}$, was low with values around 0.7 . Such a low Ångström exponent is typical for wildfire smoke.

The striking feature for the dominance of smoke particles is, however, the observed pronounced inverse spectral dependence 5 of the extinction-to-backscatter or lidar ratio together with the comparably large $532 \mathrm{~nm}$ lidar ratios of 70-90 sr (Fig. 6c). This is typically found in cases of aged smoke after long-range transport (Müller et al., 2005; Haarig et al., 2018; Ohneiser et al., 2020). Arctic haze, which may also contain aged biomass burning particles, is also able to produce an inverse spectral behavior of the lidar ratio (Ritter et al., 2016; Engelmann et al., 2020). From the clear wavelength dependence of the lidar ratio, we concluded that the impact of sulfuric-acid droplets originating from the Raikoke volcanic eruption in June 2019 must have been small. Mattis et al. (2010) measured volcanic particle lidar ratios three months after the eruption of the Sarychev volcano $\left(48^{\circ} \mathrm{N}, 153^{\circ} \mathrm{E}\right)$ in 2009 and found stratospheric lidar ratios of $40 \pm 10 \mathrm{sr}$ at both wavelengths. This is in agreement with detailed simulation studies of the optical properties of volcanic aerosol by Wandinger et al. (1995) and Jäger and Deshler (2003). By assuming the same lidar ratio of $40 \mathrm{sr}$ at 355 and $532 \mathrm{~nm}$ for volcanic particles and a typical difference between the 532 and $355 \mathrm{~nm}$ lidar ratio of 25-30 sr for aged wildfire smoke (see recent review in Haarig et al. (2018)) the clear lidar ratio difference of 20-25 sr as given in Fig. 6 and 7 is only consistent with a volcanic aerosol fraction of $\leq 20 \%$. It is worthwhile to emphasize in this context that such an unambiguous aerosol typing is only possible with dual-wavelength lidars permitting the independent retrieval of backscatter, extinction, lidar ratio and depolarization ratio, and, most important, of the spectral dependencies of these optical properties.

The particle and volume linear depolarization ratio in Fig. $6 \mathrm{~b}$ and $7 \mathrm{~b}$ were very low at both laser wavelengths of 355 and $532 \mathrm{~nm}$ and indicated the presence of spherical particles. Differences between the KARL and Polly observations in Fig. 7b are insignificant. Both, the volcanic as well as the smoke particles were spherical according to the lidar observations. The main phase of smoke particle aging obviously occurred already in the troposphere during the first days after emission. Assuming a core-shell structure of the smoke particles (Dahlkötter et al., 2014; Yu et al., 2019; Gialitaki et al., 2020), slight deviations from the spherical shape (e.g., caused by an irregular black-carbon-containing core structure) can lead to depolarization ratios of up to 0.25 at $355 \mathrm{~nm}$ and 0.2 at $532 \mathrm{~nm}$ (Haarig et al., 2018; Gialitaki et al., 2020; Ohneiser et al., 2020). This core structure gets compact (or collapses) during the aging process so that the particles become spherical and the depolarization ratios are close to zero.

Lidar observations at Leipzig $\left(51.3^{\circ} \mathrm{N} 12.4^{\circ} \mathrm{E}\right)$ in July and August 2019 corroborate the interpretation of the MOSAiC lidar observations. Clear smoke signatures in a stratospheric layer from 9.5-14 km (14 August 2019) and 12-16 km (23 August 2019) were observed in terms of the measured extinction-to-backscatter ratios (lidar ratios of 50-75 $\mathrm{sr}$ at $355 \mathrm{~nm}$ and of 75 $110 \mathrm{sr}$ at $532 \mathrm{~nm}$ ). The stratospheric AOT showed values of 0.08-0.1 at $532 \mathrm{~nm}$. The particle depolarization ratios were low and indicated spherical smoke particles. In agreement with the lidar measurements at Capel Dewi Atmospheric Observatory, close to Aberystwyth in west Wales $\left(51.3^{\circ} \mathrm{N}, 12.4^{\circ} \mathrm{W}\right)$, United Kingdom reported by Vaughan et al. (2020), we observed clear volcanic aerosol signatures over Leipzig on 10 and 23 July 2019 (before first fire smoke plumes from Siberia reached central Europe). The lidar ratios were similar and around $30 \mathrm{sr}$ at 355 and $532 \mathrm{~nm}$ wavelengths on 10 July and again similar and 
roughly between 30-60 sr on 23 July. The layer extended from the tropopause at $11 \mathrm{~km}$ to $12.5 \mathrm{~km}$ height (10 July) and from 14-16.5 km (23 July). The AOT at $532 \mathrm{~nm}$ was about 0.01-0.015 (10 July) and 0.02-0.03 (23 July). The depolarization ratio was rather low and indicated spherical sulfuric-acid droplets.

Figure 8 and Table 1 provide information on the underlying microphysical properties of the Arctic smoke and summarize the main optical and microphysical particle characteristics discussed above for the two days (25 October and 7 November 2019 ) and for another observation taken on 13 October 2019. The volume size distributions shown in Fig. 8 were obtained from the Polly observation by applying the lidar inversion method to the layer-mean three backscatter and two extinction coefficients (Veselovskii et al., 2012). All size distributions are normalized so that the integral over each shown size distribution is one. The $532 \mathrm{~nm}$ extinction profiles in Fig. 6c were used to estimate mass and surface-area concentration profiles by applying the conversion factors for the polar smoke in Ansmann et al. (2020). Surface area values of $0.2-0.4 \mathrm{~cm}^{2} \mathrm{~m}^{-3}$ in the center of the smoke layer in Fig. 8 correspond to $20-40 \mu \mathrm{m}^{2} \mathrm{~cm}^{-3}$. This latter unit is typically used in PSC studies (Jumelet et al., 2008, 2009). These surface area values are in the same range as found for PSC particle layers.

The findings agree well with many in-situ observations of long-transported aged smoke (Fiebig et al., 2003; Petzold et al., 2007; Dahlkötter et al., 2014). As typical for smoke layers, a well-defined accumulation mode was found. A distinct coarse mode was absent. The sharp edge of the size distribution towards larger particles may indicate an efficient removal of the large smoke and volcanic particles during the several-month long-term travel. The effective radii of the smoke particles were relatively small with values from 0.2-0.25 $\mu \mathrm{m}$. As shown by Müller et al. (2007) for smoke layers in the middle troposphere, the particles can grow to large sizes (with effective radii close to $0.35 \mu \mathrm{m}$ ) as a result of particle aging during long-range travel. However, as discussed by Das et al. (2020), the relatively low effective radii may be the result of the missing impact of pyroCb activity in the case of the Siberian fires in July and August 2019. The larger effective particle size for pyroCb-sourced smoke (Haarig et al., 2018; Ohneiser et al., 2020) is possibly due to the rapid coagulation of the individual aerosol particles in dense smoke plumes emitted from extreme pyroCb events combined with the removal of the larger smoke and volcanic particles. The found smoke particle surface area concentrations in Table 1 are similar to typical PSC particle surface area concentrations and thus may have provided relevant sites for ozone-depleting heterogeneous chemical processes.

The values for the refractive index (real part $n_{\text {real }}$, imaginary part $n_{\text {imag }}$ ) and the single scattering albedo SSA in Table 1 of the polar smoke are in good agreement with respective findings of Dubovik et al. (2002) based on extended sunphotometer observations of North American wildfire smoke ( $n_{\text {real }}=1.5 \pm 0.4, n_{\text {imag }}=0.0094 \pm 0.003$, and SSA $=0.94 \pm 0.2$ ). However, our refractive index and SSA values are highly uncertain and must therefore be interpreted with care. Wandinger et al. (2002) showed cases of Canadian wildfire smoke for which SSA was 0.8 and $n_{\text {imag }}$ around 0.05. The articles of Müller et al. (2005) (Canadian and Siberian wildfires) and Tesche et al. (2011) (agricultural fires in central western Africa) provide an impression of the large spread of possible values for SSA and the imaginary part of the refractive index for smoke. The values can range from 0.63 to 0.98 (SSA) and from 0.001 to 0.07 ( $n_{\text {imag }}$ ) according to these two papers. Correspondingly large differences can be found in terms of the lidar ratio (about 30 to $110 \mathrm{sr}$ for $532 \mathrm{~nm}$ ). These large ranges of values reflect that smoke can show rather different properties in terms of chemical composition, black carbon fraction, and particle size depending on fire type (flaming vs smoldering), burning material, and environmental conditions during the aging process shortly after emission and 
during long-range transport in the troposphere or in the stratosphere. When discussing polar smoke properties one needs to keep in mind that these observations are hard to compare with smoke properties at other places around the globe. The smoke (observed from October to May) circulated around the North Pole in total darkness at very low temperatures for months, and it is simply unknown in which way the smoke chemical and physcial properties change with time and how they influence the optical properties of the aged smoke and contributed to the strong ozone reductions in winter and spring of 2020 . This will be further discussed in the next subsection.

\subsection{The UTLS Arctic smoke layer from August 2019 to May 2020}

An overview of our MOSAiC smoke observation aboard the drifting RV Polarstern is presented in Fig. 9. One set of lidar products per day is considered. Gaps in the data time series in Fig. 9a are caused by fog and low-cloud events, partly lasting over many days. We included KARL observations at Spitsbergen in Fig. 9b and c to prolong the AOT and extinction time series and to better link the strong contribution of the Siberian fires (mid July to mid August 2019) to the UTLS aerosol load in the Arctic. Furthermore, we show the KARL data to emphasize the good agreement between the different lidar observations and that the smoke and volcanic aerosol mixture covered large areas in the Arctic as it was also reported by (Kloss et al., 2021). According to the KARL observations, the UTLS AOT reached values around 0.25 at $532 \mathrm{~nm}$ in the beginning of August 2019 and decreased to values of 0.1-0.15 in the second half of August 2019 and thus were similar to the stratospheric AOT values of close to 0.1 as observed over Leipzig at $52^{\circ} \mathrm{N}$ in central Europe on 14 and 23 August 2019 (see discussion in Sect. 1).

Figure 9a shows the temporal evolution of the geometrical properties of the smoke layer as observed close to the North Pole during the winter half year. The UTLS aerosol layer extended, on average, from 7-8 km to 17-18 km height. The smoke layer base was always close to the tropopause. Figure 10 provides details of the smoke layer depths. As can be seen, the vertical extent of the smoke layer was most frequently between 7 and $11 \mathrm{~km}$ (in $80 \%$ out of all cases). By comparing the 2019 with the 2020 observations, it can also be seen that the layer thickness increased with time. The layer top reached greater heights in 2020. This was probably caused by advection of smoke (and enhanced ozone) containing air masses from lower latitudes, as will be discussed further in Sect. 4.

The vertical bars in Fig. 9a are colored to distinguish different levels of particle backscattering and extinction. The backscatter coefficients at $532 \mathrm{~nm}$ were multiplied by a lidar ratio of $85 \mathrm{sr}$ to obtain the respective value of the extinction coefficient. The maximum light-extinction values were found around or just above the tropopause. A trend of downward motion of the smoke layer in terms of the optical properties is not visible. The extinction coefficients around the tropopause slowly decreased with time from values $>10 \mathrm{Mm}^{-1}$ in October and November to $<5 \mathrm{Mm}^{-1}$ in April 2020 (Fig. 9a).

The vertically non-symmetric distribution of the aerosol concentration (here expressed in terms of light extinction) with the maximum close to the base of the smoke layer may indicate an efficient removal of the particles in the troposphere by cirrus formation and ice crystal sedimentation processes. Once the aerosol particles reached the heights below the tropopause due to gravitational settling or downward mixing, they became obviously efficiently deposited by scavenging and precipitation processes. A part of the smoke particles may have served as ice-nucleating particles (Engelmann et al., 2020). 
Figure 9a also contains information about the occurrence of PSCs. Most of the PSCs over Polarstern were detected in January 2020. A measurement from 15 January 2020 is presented in Fig. 11. According to the PSC classification scheme (Achtert and Tesche, 2014), we observed a type Ib PSC. This type is made up of supercooled liquid ternary solutions that consist of $\mathrm{H}_{2} \mathrm{SO}_{4}, \mathrm{HNO}_{3}$, and $\mathrm{H}_{2} \mathrm{O}$. PSCs were most frequently found in the upper part of or above the smoke layer. All in all, we observed a much lower number of PSCs over the North Pole region $\left(86^{\circ}\right.$ to $\left.88.6^{\circ} \mathrm{N}\right)$ during the winter and spring seasons of

52020 than the CALIPSO lidar within the latitudinal range from $60^{\circ}$ to $81.8^{\circ} \mathrm{N}$ where most of the ozone depletion occurred as discussed in Sect. 4. We corrected our stratospheric smoke observations in Fig. 9 for clearly identified PSC effects. But weak PSC effects remained in the optical data for January and February as was mentioned in Sect. 2 and is visible in Fig. 12a and c by slightly enhanced depolarization ratios and decreased Ångström exponents as discussed below. The remaining PSC impact on the AOTvalues was estimated to be of the order of $<5 \%$.

Figure $9 \mathrm{~b}$ provides an overview of the development of the aerosol optical thickness (AOT) at 355 and $532 \mathrm{~nm}$ from August 2019 to May 2020. We computed the AOT from the particle backscatter height profiles in order to reduce the noise in the lidar AOT observations significantly and thus to better see trends in the evolution of the polar smoke layer. The directly determined extinction profiles were too noisy, especially in 2020. The $355 \mathrm{~nm}$ and $532 \mathrm{~nm}$ backscatter coefficients were multiplied by the statistically mean lidar ratio of $55 \mathrm{sr}$ at $355 \mathrm{~nm}$ and $85 \mathrm{sr}$ at $532 \mathrm{~nm}$, respectively. The lidar ratio time series for both wavelengths are shown in Fig. 12b. Subsequently, we integrated the extinction values between the smoke layer base and top heights as given in Fig. 9a.

The combined KARL and Polly observations show a coherent downward trend in the AOT time series until the beginning of December 2019. The $532 \mathrm{~nm}$ AOT observed over the Polarstern decreased from 0.05-0.12 in October and November to values of 0.03-0.06 from December to mid of March, and then dropped to 0.01-0.02 in April 2020. Almost constant AOT conditions were observed from 10 December to 10 March. During this time period, the extraordinarily strong polar vortex was well established and advection of smoke for southern latitudes and smoke removal processes in the upper tropopshere over the North Pole area widely equalized. The vortex collapsed around 20 April (Lawrence et al., 2020). Based on the KARL and Polly observations, we can conclude that the UTLS perturbation decreased from about 0.2 (532 nm AOT) in the beginning of August 2019 to 0.02 at the end of April 2020 (within 9 months), thus, the e-folding decay time was about 4 to 4.5 months.

The layer mean $532 \mathrm{~nm}$ smoke extinction coefficients in Fig. 9c (obtained from AOT divided by the respective layer geometrical depth in Fig. 9a) were of the order of $10 \mathrm{Mm}^{-1}$ until mid of November 2019, and around 4-5 Mm $\mathrm{Mm}^{-1}$ during the main winter months until mid of March 2020 and mostly $\leq 3 \mathrm{Mm}^{-1}$ at the end of the life time of the smoke layer. According to longterm observation at mid-latitudinal lidar sites, the minimum $532 \mathrm{~nm}$ AOT value for a clean stratosphere is around 0.0010.002 (Sakai et al., 2016; Baars et al., 2019) and the minimum extinction coefficients are of the order of $0.1-0.2 \mathrm{Mm}^{-1}$. The Ångström exponent calculated from the extinction values of 355 and $532 \mathrm{~nm}$ was on average 0.65 , which is a typical value for wildfire smoke. The Ångström exponent exceeds 1.0 when volcanic aerosol is main component of the UTLS aerosol mixture. From the measured layer mean extinction coefficients, mass concentrations of the smoke particles were derived and ranged from 0.4-2 $\mu \mathrm{g} \mathrm{m}^{-3}$ during the autumn and winter months. Minimum stratospheric mass concentrations (at mid latitudes) are 
close to 0.01-0.02 $\mu \mathrm{g} \mathrm{m}^{-3}$ (Baars et al., 2019). The shown surface area concentrations of $0.05-0.2 \mathrm{~cm}^{2} \mathrm{~m}^{-3} \mathrm{or}^{5-20} \mu \mathrm{m}^{2} \mathrm{~cm}^{-3}$ are in same range as the ones for typical PSCs (Jumelet et al., 2008, 2009) as mentioned.

We compared our UTLS AOT observations with respective satellite aerosol retrievals discussed by Kloss et al. (2021). From OMPS-LP (Ozone Mapping Profiler Suite Limb Profiler) measurements at $675 \mathrm{~nm}$, they found AOT mean values (integrated over all longitudes for the latitide of $80^{\circ} \mathrm{N}$, converted to $550 \mathrm{~nm}$ ) for the height range above the tropopause of about $0.025-0.03$ in September and October 2019, and around 0.01 (1-20 May 2020). The KARL and Polly observations revealed stratospheric

5 AOT contribution for $532 \mathrm{~nm}$ of about 0.05-0.08 (mid September to mid October 2019), and 0.01-0.02 (April-May 2020) and thus a factor of 2-3 higher values for the autumn-2019 months then retrieved by using passive remote sensing methods (Kloss et al., 2021).

Figure 12 presents the time series of the layer mean intensive particle properties. In contrast to the extensive properties in Fig. 9b and c, the depolarization ratio, lidar ratio, and backscatter-related Ångström exponents show no dependence on time. The aerosol properties remained almost unchanged over the entire winter half year. Particle coagulation or signifant removal processes, influencing the size distribution and thus the Ångström exponent, are not visible. The increasing variability in the depolarization ratios starting in January 2020 and a weak trend in the Ångström exponent for the 532-1064 nm wavelength range towards lower values are related to a non-perfect removal of weak PSC effects on the lidar signal profiles. Table 2 contains the respective mean values of the intensive aerosol properties. Again, a clear smoke signature is visible in Fig. 12 and Table 2, expressed by the inverse wavelength dependence of the lidar ratio and the rather different Ångström exponents for backscattering and extinction.

Figure 13 shows monthly mean profiles of the $532 \mathrm{~nm}$ particle extinction coefficient. The same lidar data as in Fig. 9c are used here, i.e., the height profiles of the particle backscatter coefficient at $532 \mathrm{~nm}$ were multiplied by a lidar ratio of $85 \mathrm{sr}$ and then separately averaged for each of the shown seven months. As can be seen, there is clear separation between the aerosol within the polar dome (Stohl, 2006; Bozem et al., 2019) and above this isolated polar air mass. The vertical depth of the polar dome increased from October to Februay. The smoke layer maximum is close to but above the tropopause for the period from October to February. The smoke particle concentration decreased with time from October to April, however, the remarkable similarity of the the three profiles for the central winter months (December to February) indicates again the strong impact of the polar vortex on the polar aerosol conditions to provide steady state conditions for advection from more southern Arctic latitudes and removal of smoke when entering the troposphere from above. In spring (see March and April profiles), with the returning sunlight, changing meteorological conditions including the impact of absorption of solar radiation by the smoke, the stable polar stratification of different air masses started to collapse. We finally estimated the smoke aerosol load over the Arctic by multiplying the area (considering latitudes $>66.7^{\circ} \mathrm{N}$ ) by a mean smoke layer depth of $8 \mathrm{~km}$, a mean smoke extinction coefficient of about $5 \mathrm{Mm}^{-1}$, a volume-to-extinction conversion factor of $0.124 \cdot 10^{-12} \mathrm{Mm}$ for wildfire smoke (Ansmann et al., 2020), and the smoke particle density of $1.15 \mathrm{~g} \mathrm{~m}^{-3}$, and yield $0.2 \mathrm{Mt}$ of smoke as a guess for the mean value of the smoke aerosol load over the Arctic during the winter halfyear 2019-2020. 


\subsection{Comparison with foregoing Arctic aerosol studies}

In Fig. 14, we compare our polar aerosol observations performed between $85^{\circ}-88.6^{\circ} \mathrm{N}$ in the autumn and winter seasons of 2019-2020 with CALIPSO long-term observations of Arctic aerosol profiles (Di Pierro et al., 2013; Di Biagio et al., 2018; Yang et al., 2020) and retrievals of the particle extinction coefficient from satellite-based OMPS-LP and Stratospheric Aerosol and Gas Experiment (SAGE) II and III observations (Treffeisen et al., 2006; Taha et al., 2021). In this way, a consistent, vertically resolved view on the aerosol condition in the Central Arctic during the winter half year almost up to $30 \mathrm{~km}$ is provided, to our knowledge, for the first time.

The following satellite data sets are used. Di Pierro et al. (2013) analyzed CALIPSO lidar observations at $532 \mathrm{~nm}$ and considered all data collected within the latitudinal belt from $70^{\circ}-81.8^{\circ} \mathrm{N}$ from June 2006 to December 2012 . However, as we can see in Fig. 14, the applied CALIPSO version 3 data analysis obviously removed too many dense smoke and haze layers because of an improper aerosol/cloud discrimination procedure. Dense smoke layers were probably interpreted as thin or subvisible cirrus and removed from the aerosol data base.

Yang et al. (2020) analyzed Arctic CALIPSO observations for the latitudinal belt from $65^{\circ}-81.8^{\circ} \mathrm{N}$ for the time period from June 2006 to December 2019 and made use of the latest data analysis version 4 with an improved aerosol/cloud discrimination scheme. The shown seasonal mean height profiles are in good agreement with our measurement. Since these observations include observations of the UTLS smoke from the major Canadian fires in 2017 (Baars et al., 2019) and the huge fires in Siberia in the summer of 2019, they are close to our 2019-2020 profile observations. The 13-year mean autumn profile, shown in Fig. 14, suggests a strong and regular contributions from wildfires to the polar aerosol load in the middle troposphere in late summer and autumn.

Di Biagio et al. (2018) combined ground-based lidar observations between $80^{\circ}-83^{\circ} \mathrm{N}$ and $7^{\circ}-27^{\circ} \mathrm{E}$ (north of Svalbard) from October 2014 to June 2015 with CALIPSO observations from $80^{\circ}-81.8^{\circ} \mathrm{N}$ and $5^{\circ}-25^{\circ} \mathrm{E}$ to obtain an improved knowledge of the wintertime aerosol conditions in the high Central Arctic. The ground-based lidars were operated at $800 \mathrm{~nm}$ and mounted on autonomous drifting buoys (IAOOS: Ice-Atmosphere-Ocean Observing System platforms) and made, for the first time, aerosol observations at latitudes up to $83^{\circ} \mathrm{N}$ during the winter season.

All aerosol profiles derived from CALIPSO lidar observation stop at $12 \mathrm{~km}$. At greater heights the signal-to-noise ratio is too low to permit a proper aerosol retrieval for a trustworthy multiyear statistics. A discussion on the sensitivity of the CALIPSO lidar in the case of Arctic aerosol is given by Di Biagio et al. (2018).

25 Treffeisen et al. (2006) analyzed SAGE II and III data for $525 \mathrm{~nm}$ and were able to present, for the first time, an annual cycle of aerosol vertical layering from $4-12 \mathrm{~km}$ for $60^{\circ}-80^{\circ} \mathrm{N}$. Data collected from 2001-2006 were used in Fig. 14. The SAGE II and III measurements are obviously representative for typical background aerosol conditions.

Taha et al. (2021) analyzed OMPS-LP data and SAGEIII/ISS (International Space Station) observations and provide aerosol information for the height levels of $18.5,20.5$, and $25.5 \mathrm{~km}$ height (2017-2019) for $60^{\circ} \mathrm{N}$ and $70^{\circ} \mathrm{N}$ for the wavelength of $745 \mathrm{~nm}$. The $60^{\circ}$ and $70^{\circ} \mathrm{N}$ values were used to estimate the values at $80^{\circ} \mathrm{N}$, shown in Fig. 14, via extrapolation. Taha et al. (2021) used an Ångström exponent of 1.9 to convert the satellite aerosol observations at $745 \mathrm{~nm}$ to the ones at $532 \mathrm{~nm}$. 
Baars et al. (2019) reported minimum values of the stratospheric AOT of the order of 0.001 to 0.002 at $532 \mathrm{~nm}$ and related particle extinction coefficient close to $0.1-0.2 \mathrm{Mm}^{-1}$ (see pink vertical lines from 12-20 km height in Fig. 14) derived from Raman lidar observations at Leipzig, Germany, from January 2000 to June 2008 (during a period with no significant volcanic eruption and wildfire smoke events).

If we define the aerosol profile from 4-12 km of (Treffeisen et al., 2006) in combination with the curve of Taha et al. (2021) and the interpolated dashed line in Fig. 14 as the smoke-free and volcanic-aerosol-free background aerosol level, then the particle extinction coefficient was enhanced in the lower stratosphere up to about 14-15 km height by an order of magnitude in

5 the winter half year of 2019-2020. The impact of the 2019-2020 smoke layer is clearly visible from about 8 to $19 \mathrm{~km}$ height, i.e., the height range in which also the unprecedented strong ozone reduction was found from January to April 2020 (see next section).

\section{PSCs, UTLS wildfire smoke and ozone depletion}

Complex atmospheric circulation patterns (resulting from planetary and gravity wave activity) determine the meridional and

vertical transport of momentum, heat, aerosol particles, and gaseous components (ozone, $\mathrm{N}_{2} \mathrm{O}$, water vapor, etc.) towards the Arctic and from greater to lower heights within the Arctic circle (via the descending branch of the Brewer Dobson circulation). Variations in the Arctic ozone concentration are, therefore, the result or horizontal and vertical ozone transport and local chemical processes causing ozone depletion. The destruction of ozone is closely linked to chlorine activation (conversion from nonreactive forms into forms that destroy ozone) taking place on the surface of PSC particles. Because of weak planetary wave forcing in the summer and autumn of 2019, a strong, cold, and persistent polar vortex developed in the winter of 2019 (Manney et al., 2020), the strongest in the last 40 years (Lawrence et al., 2020). In the isolated Arctic air mass, temperatures dropped below the nitric acid trihydrate (NAT) PSC threshold of $-78^{\circ} \mathrm{C}$ for a long time period (from mid November 2019 to March 2020) so that favorable conditions for the formation of extended PSC fields and thus chlorine activation were given. The strongest ozone reduction ever observed in the Arctic occurred in the spring of 2020 (DeLand et al., 2020; Manney et al., 2020; Wohltmann et al., 2020; Inness et al., 2020; Wilka et al., 2021; Dameris et al., 2021; Smyshlyaev et al., 2021). Manney et al. (2020) analyzed 16-year Aura Microwave Limb Sounder (MLS) measurements and further pointed out that chlorine activation and ozone depletion began earlier than in any previously observed winter, with evidence of chemical ozone loss starting already in November 2019. Peak chlorine activation and thus peak ozone loss occurred at lower altitudes in 2020 as usual. The prolonged polar processing in 2019/2020 resulted in substantial low $\mathrm{O}_{3}$ anomalies beginning in early January 2020.

Because of the unusual stratospheric smoke situation in the Arctic in 2019-2020, the question arises to what extent the long lasting aerosol perturbation in the lowest part of the Arctic stratosphere may have contributed to the pronounced ozone reduction? According to HYSPLIT backward trajectories (HYSPLIT, last access: 5 January, 2021) and ground-based Raman lidar observations of the Alfred Wegener Institute at Spitsbergen and over the Polarstern, the smoke layer covered large parts of the Arctic. The CALIPSO lidar data were of limited use here to describe the smoke situation over the Arctic. The data base (CALIOP, last access: 5 January, 2021) does not contain any clear hint on the Arctic smoke layer. The reason is probably 
that the smoke layer showed no sharp edges, was rather homogeneous, and the smoke backscatter coefficients were too low to be unambiguously identified as stratospheric aerosol in the noisy CALIPSO signal profiles. Di Biagio et al. (2018) discussed CALIPSO lidar detection limits in the case of Arctic aerosol observations and corroborate our hypothesis. This circumstance is probably also the reason that non of the recent papers (mentioned above) dealing with the record-breaking ozone depletion considered this strong stratospheric aerosol perturbation in their explanations and discussions.

The overall question can be split into three more precise research questions: 1) How did the optically thick wildfire smoke layers influence the atmospheric circulation pattern (and planetary wave driving) at high northern latitudes in the summer and

5 early autumn of 2019 by absorbing solar radiation and heating of the air? Large scale warming may have indirectly contributed to create favorable conditions for the development of a strong vortex. 2) To what extent did the wildfire smoke particles influence the evolution of PSCs and specifically their microphysical properties (number concentration, size distribution) (Hoyle et al., 2013; Zhu et al., 2015, 2018)? 3) To what extent were the wildfire particles directly involved in heterogeneous chemical processes by increasing the particle surface area available to convert nonreactive chlorine components into reactive forms?

The wildfire smoke particles in the stratosphere were probably glassy, showed a core-shell morphology, and were probably largely composed of organic material (organic carbon, OC, in the shell) and, to a minor part, of black carbon (BC, concentrated in the core part). The volcanic aerosol particles (sulfuric-acid particles) and the smoke particles were most likely widely externally mixed, however, collisions and coagulation of smoke and volcanic aerosol particles leading to internally mixed particles cannot be excluded. Changes in the morphology (size, shape, and internal structure) of smoke particles and their internal mixing state were ongoing during the long-range transport.

The smoke-PSC-ozone research field is meanwhile (since 2017) as important as the studies on the impact of stratospheric volcanic aerosol on ozone depletion (Ansmann et al., 1996; Zhu et al., 2018) because major wildfire smoke events may occur frequently in future as a result of climate change as discussed in the introduction. It is interesting to note in the context that the stratospheric aerosol conditions in both hemispheres (2019 in the northern hemisphere, 2020 in the southern hemisphere) (Ohneiser et al., 2020; Khaykin et al., 2020; Kablick et al., 2020; Kloss et al., 2021) were significantly perturbed by wildfire smoke, and in both hemispheres record-breaking ozone depletion was reported (https://public.wmo.int/en/media/news/ record-breaking-2020-ozone-hole-closes) and occurred in a smoke-polluted stratospheric environment.

The goal of this section is to provide a composite view on the Artic ozone situation 2019-2020 based on CALIPSO PSC observations, our MOSAiC smoke and PSC observations, and MOSAiC ozone profiles measured with sondes launched from Polarstern. The data may serve as a useful guide for an improved atmospheric modeling of this record-breaking ozone-depletion event with the specific aim to clearify the role of smoke in the complex ozone depletion processes.

The MOSAiC and CALIPSO measurements are shown in Fig. 15 and 16. 40 ozone sondes were launched during the sevenmonth period from October 2019 to may 2020 (von der Gathen and Maturilli, 2020; Wohltmann et al., 2020). 13 out of the 40 sondes were launched from the beginning of March to mid of April 2020 and thus during the period with lowest ozone concentration.

To obtain an idea about the impact of the PSCs on chlorine activation and subsequent ozone destruction, we analyzed the CALIPSO observations in the latitudinal belt from $60^{\circ} \mathrm{N}$ to $80^{\circ} \mathrm{N}$ on a daily basis. The pink lines in Fig. 15 indicate the height 
range in which PSCs were detected. The top of the PSC height range was always easy to identify in the CALIPSO observations. The base height must be exercised with care because the lowermost PSCs may have produced too weak backscatter and were then not clearly detectable in the noisy CALIPSO data. According to the MOSAiC radiosondes launched four times a day aboard Polarstern, the lowest temperatures occurred between $15 \mathrm{~km}$ and $27 \mathrm{~km}$ height in the central winter (December 2019 to March 2020). The PSC relevant temperatures of $<-78^{\circ} \mathrm{C}$ were found between $18 \mathrm{~km}$ and $27 \mathrm{~km}$ height in December 2019 and continuously propagated downward to about $15-23 \mathrm{~km}$ height in early March 2020. This height range of low temperatures coincides well with the PSC height range in Fig. 15 and also with the respective PSC retrievals presented by DeLand et al. (2020).

In addition to the PSC height range, the time series of the smoke layer base and top heights as well as of the tropopause height are shown in Fig. 15. As can be seen in the composite figure, a layer with very low ozone partial pressure between 15 and $20 \mathrm{~km}$ height crossed the Polarstern in March and April 2020 (until the Polar vortex collapsed around 20 April). This layer of low ozone concentration coincides with the PSC height range in which chlorine activation occurred in the months before. The smoke layer, extending roughly from the tropopause to $15-18 \mathrm{~km}$ height did not overlap with the region with very low ozone concentration in the spring of 2020, and also not with the PSC height range until mid of January 2020. Horizontal ozone transport above the smoke layer was probably responsible for the local ozone maximum between 15 and $20 \mathrm{~km}$ height until 10 December 2019. Later on, ozone-rich and smoke-rich air became advected from lower latitudes and as consequence the smoke layer height increased in December, and afterwards followed the enhanced ozone signature from mid December to mid March. Since mid of January 2020, the layer with enhanced ozone concentration was influenced by both, smoke and PSCs.

To obtain a more clear picture on ozone depletion during the winter and spring season 2019-2020, Fig. 16 presents ozone deviations from the long-term mean values as discussed by Inness et al. (2020) together with the PSC and smoke layer information. Also, the PSC observations with the Polarstern lidar are included. Inness et al. (2020) used a reanalysis dataset produced by the Copernicus Atmosphere Monitoring service (CAMS, reanalysis, 2003-2019) to describe the evolution of the 2020 Arctic ozone season and to compare it with years back to 2003. Inness et al. (2020) pointed out that the December anomaly may be due to the observed and modeled reduced meridional mixing because of reduced wave activity. However, there is a clear signature of chemical ozone depletion leading to the extremely low ozone values over the North Pole in March and April 2020. In March 2020, ozone values in the ozone layer over the North Pole were partly reduced to more than $10 \mathrm{mPa}$ below the climatological values. Again, we notice a clear link between PSC occurrence and anomalously large ozone reduction. But we see a large vertical overlap between the smoke layer and the height range with strong negative ozone deviations. As was mentioned by Manney et al. (2020), the height range with strong ozone anomalies reached down to unusually low heights and thus to heights where smoke was permanently present. Surface area concentrations of the smoke particles were in the same range of typical values for Arctic PSCs (as shown in Fig. 9). All in all, Fig. 16 may motivate future studies on the interplay between smoke, PSCs, and ozone depletion based on advanced modelling in a way presented by Zhu et al. (2018) in the case of an additional impact of volcanic aerosol on ozone depletion. 


\section{Summary and outlook}

We presented a detailed optical and microphysical characterization of an unexpected UTLS smoke layer over the North Pole region in the winter half year of 2019-2020. Never before, such a strong perturbation of the stratospheric aerosol conditions in the High Arctic was measured and reported. For the first time, the spread of smoke of a major forest fire event up to stratospheric heights could be explained by self-lifting effects, and thus without the need of pyroCb convection. The majority of the smoke originated from strong, long-lasting wildfires in Siberia in July and August 2019. A month earlier, the Raikoke volcano erupted and the resulting stratospheric sulfuric-acid aerosol layers also covered large parts of the northern hemisphere.

5 We emphasized the need for a dual wavelength lidar, such as the Polarstern Polly operated during the MOSAiC expedition, to unambiguously identify the prevailing aerosol type based on the spectral dependence of the lidar ratio. We estimated the impact of volcanic aerosol contribution to the overall stratospheric aerosol mass concentration to <20\%. The UTLS smoke AOT at $532 \mathrm{~nm}$ ranged from 0.05-0.12 in October-November 2019 and was of the order of 0.03-0.06 during the central winter months (December-February). The observed extinction-to-backscatter ratios (lidar ratios) were, on average, 55 sr at the wavelength of $355 \mathrm{~nm}$ and of $85 \mathrm{sr}$ at $532 \mathrm{~nm}$ as typical for moderately light-absorbing smoke. The light-extinction-related 355-532 nm Ångström exponent of around 0.65 also clearly indicated that smoke particles dominated.

Based on an extended review of the literature dealing with aerosol profile observations in the Arctic, we were able to develop a coherent picture on aerosol structures and layering features for the autumn and winter seasons up to $27 \mathrm{~km}$ height. In the next step, we will analyze the MOSAiC lidar observations of the summer halfyear to fully cover the annual cycle of Arctic aerosol conditions as a function of height.

We discussed, to our knowledge for the first time, a potential impact of the wildfire smoke aerosol on the record-breaking ozone depletion over the Arctic in the spring of 2020 based on vertically resolved information on PSC and smoke occurrence and strength of ozone depletion. This discussion may initiate in-depth modeling studies to clarify the role of wildfire smoke in stratospheric PSC formation and ozone reduction processes. If follow-on studies will indicate a link between huge fires (caused by unusually hot temperatures and droughts as a result of climate change), corresponding smoke occurrence in the lower stratosphere, and severe ozone depletion in the Arctic and Antarctica, the climate change debate will be added by a new, and until now, not considered important aspect.

As one of another important follow-on tasks, we will explore the potential of wildfire smoke to influence cirrus formation during the winter half year. A first case study was discussed in Engelmann et al. (2020). Furthermore, we will contrast these results with ones of similar studies of aerosol-cirrus interaction during the summer half year when long-range transport of anthropogenic haze mixed with mineral dust from Asia, Europe, and North America as well as episodic wildfire smoke events prevailed.

\section{Data availability}

Polly lidar observations (level 0 data, measured signals) are in the PollyNET data base (PollyNet, last access: 5 January, 2021) with quicklooks at http://polly.tropos.de. All the analysis products are available at TROPOS upon request (polly@tropos.de). 
KARL lidar can be provided by AWI upon request. CALIPSO observations were downloaded from the CALIPSO data base (CALIOP, last access: 5 January, 2021), Fire and MODIS data are available at the NASA data base (FIRMS, last access: 5 January, 2021; MODIS, last access: 5 January, 2021). The radiosonde and ozonesonde data (von der Gathen and Maturilli, 2020) are currently as well available via the MCS. PANGAEA is the primary long-term archive for the MOSAiC data set.

\section{Author contributions}

The paper was designed and written by KO, AA, and RE. The data analysis was performed by KO, RE, CR, AC, IV, HB, and HG. The co-authors RE, HGr, MR, JH, and DA took care of the lidar observations aboard Polarstern during the MOSAiC year.

$5 \mathrm{SD}$ and MM were responsible for radiosonde and ozonesonde measurements.

\section{Competing interests}

The authors declare that they have no conflict of interest.

\section{Financial support}

The data was produced as part of the international Multidisciplinary drifting Observatory for the Study of the Arctic Climate (MOSAiC) with the tag MOSAiC20192020 and Project ID AWI_PS122_00. This project has also received funding from the European Union's Horizon 2020 research and innovation program ACTRIS-2 Integrating Activities (H2020-INFRAIA2014 - 2015, grant agreement no. 654109). We gratefully acknowledge the funding by the Deutsche Forschungsgemeinschaft (DFG, German Research Foundation) - project no. 268020496 - TRR 172, within the Transregional Collaborative Research Center "ArctiC Amplification: Climate Relevant Atmospheric and SurfaCe Processes, and Feedback Mechanisms (AC)3". The (project no. 16-17-10241).

The publication of this article was funded by the Open Access Fund of the Leibniz Association.

Acknowledgements. We are grateful to the MOSAiC teams and the RV Polarstern crew for their perfect logistical support. We further thank the entire radiosonde and ozonesonde team, especially AWI, DWD, ARM, Jürgen (Egon) Graeser, and all volunteers for their enormous efforts of producing the exemplary and uninterrupted MOSAiC dataset. 


\section{References}

Achtert, P. and Tesche, M.: Assessing lidar-based classification schemes for polar stratospheric clouds based on 16 years of measurements at Esrange, Sweden, Journal of Geophysical Research: Atmospheres, 119, 1386-1405, https://doi.org/10.1002/2013JD020355, 2014.

ACTRIS: Aerosols, Clouds and Trace gases Research InfraStructure home page, https://www.actris.eu/, last access: 5 January, 2021.

Ansmann, A., Wagner, F., Wandinger, U., Mattis, I., Görsdorf, U., Dier, H.-D., and Reichardt, J.: Pinatubo aerosol and stratospheric ozone reduction: Observations over central Europe, Journal of Geophysical Research: Atmospheres, 101, 18775-18785, https://doi.org/https://doi.org/10.1029/96JD01373, 1996.

5 Ansmann, A., Ohneiser, K., Mamouri, R.-E., Knopf, D. A., Veselovskii, I., Baars, H., Engelmann, R., Foth, A., Jimenez, C., Seifert, P., and Barja, B.: Tropospheric and stratospheric wildfire smoke profiling with lidar: Mass, surface area, CCN and INP retrieval, in review, Atmospheric Chemistry and Physics Discussions, 2020, 1-45, https://doi.org/10.5194/acp-2020-1093, 2020.

ARM: (Atmospheric Radiation Measurement) mobile facility homepage, https://www.arm.gov/capabilities/observatories/amf, last access: 5 January, 2021.

Baars, H., Kanitz, T., Engelmann, R., Althausen, D., Heese, B., Komppula, M., Preißler, J., Tesche, M., Ansmann, A., Wandinger, U., Lim, J.-H., Ahn, J. Y., Stachlewska, I. S., Amiridis, V., Marinou, E., Seifert, P., Hofer, J., Skupin, A., Schneider, F., Bohlmann, S., Foth, A., Bley, S., Pfüller, A., Giannakaki, E., Lihavainen, H., Viisanen, Y., Hooda, R. K., Pereira, S. N., Bortoli, D., Wagner, F., Mattis, I., Janicka, L., Markowicz, K. M., Achtert, P., Artaxo, P., Pauliquevis, T., Souza, R. A. F., Sharma, V. P., van Zyl, P. G., Beukes, J. P., Sun, J., Rohwer, E. G., Deng, R., Mamouri, R.-E., and Zamorano, F.: An overview of the first decade of Polly ${ }^{\text {NET }}$ : an emerging network of automated Raman-polarization lidars for continuous aerosol profiling, Atmospheric Chemistry and Physics, 16, 5111-5137, https://doi.org/10.5194/acp-16-5111-2016, https://acp.copernicus.org/articles/16/5111/2016/, 2016.

Baars, H., Ansmann, A., Ohneiser, K., Haarig, M., Engelmann, R., Althausen, D., Hanssen, I., Gausa, M., Pietruczuk, A., Szkop, A., Stachlewska, I. S., Wang, D., Reichardt, J., Skupin, A., Mattis, I., Trickl, T., Vogelmann, H., Navas-Guzmán, F., Haefele, A., Acheson, K., Ruth, A. A., Tatarov, B., Müller, D., Hu, Q., Podvin, T., Goloub, P., Veselovskii, I., Pietras, C., Haeffelin, M., Fréville, P., Sicard, M., Comerón, A., Fernández García, A. J., Molero Menéndez, F., Córdoba-Jabonero, C., Guerrero-Rascado, J. L., Alados-Arboledas, L., Bortoli, D., Costa, M. J., Dionisi, D., Liberti, G. L., Wang, X., Sannino, A., Papagiannopoulos, N., Boselli, A., Mona, L., D’Amico, G., Romano, S., Perrone, M. R., Belegante, L., Nicolae, D., Grigorov, I., Gialitaki, A., Amiridis, V., Soupiona, O., Papayannis, A., Mamouri, R.-E., Nisantzi, A., Heese, B., Hofer, J., Schechner, Y. Y., Wandinger, U., and Pappalardo, G.: The unprecedented 2017-2018 stratospheric smoke event: decay phase and aerosol properties observed with the EARLINET, Atmospheric Chemistry and Physics, 19, 15 183-15 198, https://doi.org/10.5194/acp-19-15183-2019, 2019.

Bob Berwyn, Inside Climate News: Alaska Chokes on Wildfires as Heat Waves Dry Out the Arctic, https://insideclimatenews.org/news/ 11072019/arctic-wildfires-alaska-climate-change-heat-wave-2019-university-funding, last access: 5 January, 2021.

Boers, R., de Laat, A. T., Stein Zweers, D. C., and Dirksen, R. J.: Lifting potential of solar-heated aerosol layers, Geophysical Research Letters, 37, https://doi.org/10.1029/2010GL045171, 2010.

Bozem, H., Hoor, P., Kunkel, D., Köllner, F., Schneider, J., Herber, A., Schulz, H., Leaitch, W. R., Aliabadi, A. A., Willis, M. D., Burkart, J., and Abbatt, J. P. D.: Characterization of transport regimes and the polar dome during Arctic spring and summer using in situ aircraft measurements, Atmospheric Chemistry and Physics, 19, 15 049-15 071, https://doi.org/10.5194/acp-19-15049-2019, 2019.

CALIOP: NASA Earthdata, https://search.earthdata.nasa.gov/search?fp=CALIPSO\&fi=CALIOP, last access: 5 January, 2021. 
CAMS-1: Another active year for Arctic wildfires, Copernicus Atmosphere Monitoring Service, ECMWF, https://atmosphere.copernicus. eu/another-active-year-arctic-wildfires, last access: 5 January, 2021.

CAMS-2: Ozone hole season 2020, https://atmosphere.copernicus.eu/2020-antarctic-ozone-hole-season, last access: 5 January, 2021.

Dahlkötter, F., Gysel, M., Sauer, D., Minikin, A., Baumann, R., Seifert, P., Ansmann, A., Fromm, M., Voigt, C., and Weinzierl, B.: The Pagami Creek smoke plume after long-range transport to the upper troposphere over Europe - aerosol properties and black carbon mixing state, Atmospheric Chemistry and Physics, 14, 6111-6137, https://doi.org/10.5194/acp-14-6111-2014, 2014.

Dai, G., Althausen, D., Hofer, J., Engelmann, R., Seifert, P., Bühl, J., Mamouri, R.-E., Wu, S., and Ansmann, A.: Calibration of Raman lidar water vapor profiles by means of AERONET photometer observations and GDAS meteorological data, Atmospheric Measurement Techniques, 11, 2735-2748, https://doi.org/10.5194/amt-11-2735-2018, 2018.

Dameris, M., Loyola, D. G., Nützel, M., Coldewey-Egbers, M., Lerot, C., Romahn, F., and van Roozendael, M.: Record low ozone values over the Arctic in boreal spring 2020, Atmospheric Chemistry and Physics, 21, 617-633, https://doi.org/10.5194/acp-21-617-2021, 2021.

Das, S., Colarco, P. R., Oman, L. D., Taha, G., and Torres, O.: Pyrocumulonimbus Events over British Columbia in 2017: The Long-term Transport and Radiative Impacts of Smoke Aerosols in the Stratosphere, Atmospheric Chemistry and Physics Discussions, 2020, 1-35, https://doi.org/10.5194/acp-2020-1240, 2020.

de Laat, A. T. J., Stein Zweers, D. C., Boers, R., and Tuinder, O. N. E.: A solar escalator: Observational evidence of the self-lifting of smoke and aerosols by absorption of solar radiation in the February 2009 Australian Black Saturday plume, Journal of Geophysical Research: Atmospheres, 117, https://doi.org/10.1029/2011JD017016, 2012.

DeLand, M. T., Bhartia, P. K., Kramarova, N., and Chen, Z.: OMPS LP Observations of PSC Variability During the NH 2019-2020 Season, Geophysical Research Letters, 47, https://doi.org/10.1029/2020GL090216, 2020.

Di Biagio, C., Pelon, J., Ancellet, G., Bazureau, A., and Mariage, V.: Sources, Load, Vertical Distribution, and Fate of Wintertime Aerosols North of Svalbard From Combined V4 CALIOP Data, Ground-Based IAOOS Lidar Observations and Trajectory Analysis, Journal of Geophysical Research: Atmospheres, 123, 1363-1383, https://doi.org/10.1002/2017JD027530, 2018.

Di Pierro, M., Jaeglé, L., Eloranta, E. W., and Sharma, S.: Spatial and seasonal distribution of Arctic aerosols observed by the CALIOP satellite instrument (2006-2012), Atmospheric Chemistry and Physics, 13, 7075-7095, https://doi.org/10.5194/acp-13-7075-2013, 2013.

Dubovik, O., Holben, B., Eck, T. F., Smirnov, A., Kaufman, Y. J., King, M. D., Tanré, D., and Slutsker, I.: Variability of Absorption and Optical Properties of Key Aerosol Types Observed in Worldwide Locations, Journal of the Atmospheric Sciences, 59, 590 - 608, https://doi.org/10.1175/1520-0469(2002)059<0590:VOAAOP>2.0.CO;2, 2002.

Engelmann, R., Kanitz, T., Baars, H., Heese, B., Althausen, D., Skupin, A., Wandinger, U., Komppula, M., Stachlewska, I. S., Amiridis, V., Marinou, E., Mattis, I., Linné, H., and Ansmann, A.: The automated multiwavelength Raman polarization and water-vapor lidar Polly ${ }^{\mathrm{XT}}$ : the neXT generation, Atmospheric Measurement Techniques, 9, 1767-1784, https://doi.org/10.5194/amt-9-1767-2016, 2016.

Engelmann, R., Ansmann, A., Ohneiser, K., Griesche, H., Radenz, M., Hofer, J., Althausen, D., Dahlke, S., Maturilli, M., Veselovskii, I., Jimenez, C., Wiesen, R., Baars, H., Bühl, J., Gebauer, H., Haarig, M., Seifert, P., Wandinger, U., and Macke, A.: UTLS wildfire smoke over the North Pole region, Arctic haze, and aerosol-cloud interaction during MOSAiC 2019/20: An introductory, Atmospheric Chemistry and Physics Discussions, 2020, 1-41, https://doi.org/10.5194/acp-2020-1271, 2020.

Fiebig, M., Stohl, A., Wendisch, M., Eckhardt, S., and Petzold, A.: Dependence of solar radiative forcing of forest fire aerosol on ageing and state of mixture, Atmospheric Chemistry and Physics, 3, 881-891, https://doi.org/10.5194/acp-3-881-2003, 2003.

FIRMS: Fire Information for Resource Management System, https://firms.modaps.eosdis.nasa.gov/map/\#z:5;c:144.3,-27.9;t:adv-points;d: 
Fromm, M., Lindsey, D. T., Servranckx, R., Yue, G., Trickl, T., Sica, R., Doucet, P., and Godin-Beekmann, S.: The Untold Story of Pyrocumulonimbus, Bulletin of the American Meteorological Society, 91, 1193-1210, https://doi.org/10.1175/2010BAMS3004.1, 2010.

Gialitaki, A., Tsekeri, A., Amiridis, V., Ceolato, R., Paulien, L., Kampouri, A., Gkikas, A., Solomos, S., Marinou, E., Haarig, M., Baars, H., Ansmann, A., Lapyonok, T., Lopatin, A., Dubovik, O., Groß, S., Wirth, M., Tsichla, M., Tsikoudi, I., and Balis, D.: Is the near-spherical shape the "new black" for smoke?, Atmospheric Chemistry and Physics, 20, 14 005-14 021, https://doi.org/10.5194/acp-20-14005-2020, 2020.

GMAO: Tropopause definition (page 52), Global Modeling and Assimilation Office Goddard Space Flight Center, Greenbelt, Maryland, https://gmao.gsfc.nasa.gov/GMAO_products/documents/GEOS-5.2.0_File_Specification.pdf, 2008.

Griesche, H. J., Seifert, P., Ansmann, A., Baars, H., Barrientos Velasco, C., Bühl, J., Engelmann, R., Radenz, M., Zhenping, Y., and Macke, A.: Application of the shipborne remote sensing supersite OCEANET for profiling of Arctic aerosols and clouds during Polarstern cruise PS106, Atmospheric Measurement Techniques, 13, 5335-5358, https://doi.org/10.5194/amt-13-5335-2020, 2020.

Haarig, M., Ansmann, A., Baars, H., Jimenez, C., Veselovskii, I., Engelmann, R., and Althausen, D.: Depolarization and lidar ratios at 355, 532, and $1064 \mathrm{~nm}$ and microphysical properties of aged tropospheric and stratospheric Canadian wildfire smoke, Atmospheric Chemistry and Physics, 18, 11 847-11 861, https://doi.org/10.5194/acp-18-11847-2018, 2018.

Hofer, J., Althausen, D., Abdullaev, S. F., Makhmudov, A. N., Nazarov, B. I., Schettler, G., Engelmann, R., Baars, H., Fomba, K. W., Müller, K., Heinold, B., Kandler, K., and Ansmann, A.: Long-term profiling of mineral dust and pollution aerosol with multiwavelength polarization Raman lidar at the Central Asian site of Dushanbe, Tajikistan: case studies, Atmospheric Chemistry and Physics, 17, 14 55914 577, https://doi.org/10.5194/acp-17-14559-2017, 2017.

Hoffmann, A., Ritter, C., Stock, M., Shiobara, M., Lampert, A., Maturilli, M., Orgis, T., Neuber, R., and Herber, A.: Ground-based lidar measurements from Ny-Ålesund during ASTAR 2007, Atmospheric Chemistry and Physics, 9, 9059-9081, https://doi.org/10.5194/acp9-9059-2009, 2009.

Hoyle, C. R., Engel, I., Luo, B. P., Pitts, M. C., Poole, L. R., Grooß, J.-U., and Peter, T.: Heterogeneous formation of polar stratospheric clouds - Part 1: Nucleation of nitric acid trihydrate (NAT), Atmospheric Chemistry and Physics, 13, 9577-9595, https://doi.org/10.5194/acp-139577-2013, 2013.

HYSPLIT: HYbrid Single-Particle Lagrangian Integrated Trajectory model, backward trajectory calculation tool, http://ready.arl.noaa.gov/ HYSPLIT_traj.php, last access: 5 January, 2021.

Inness, A., Chabrillat, S., Flemming, J., Huijnen, V., Langenrock, B., Nicolas, J., Polichtchouk, I., and Razinger, M.: Exceptionally Low Arctic Stratospheric Ozone in Spring 2020 as Seen in the CAMS Reanalysis, Journal of Geophysical Research: Atmospheres, 125, https://doi.org/10.1029/2020JD033563, 2020.

Jäger, H. and Deshler, T.: Correction to "Lidar backscatter to extinction, mass and area conversions for stratospheric aerosols based on midlatitude balloonborne size distribution measurements", Geophysical Research Letters, 30, https://doi.org/10.1029/2003GL017189, 2003.

Jumelet, J., Bekki, S., David, C., and Keckhut, P.: Statistical estimation of stratospheric particle size distribution by combining optical modelling and lidar scattering measurements, Atmospheric Chemistry and Physics, 8, 5435-5448, https://doi.org/10.5194/acp-8-54352008, 2008.

Jumelet, J., Bekki, S., David, C., Keckhut, P., and Baumgarten, G.: Size distribution time series of a polar stratospheric cloud observed above Arctic Lidar Observatory for Middle Atmosphere Research (ALOMAR) $\left(69^{\circ} \mathrm{N}\right)$ and analyzed from multiwavelength lidar measurements during winter 2005, Journal of Geophysical Research: Atmospheres, 114, https://doi.org/https://doi.org/10.1029/2008JD010119, 2009. 
Kablick, G. P., Allen, D. R., Fromm, M. D., and Nedoluha, G. E.: Australian PyroCb Smoke Generates Synoptic-Scale Stratospheric Anticyclones, Geophysical Research Letters, 47, https://doi.org/10.1029/2020GL088101, 2020.

Kanitz, T., Seifert, P., Ansmann, A., Engelmann, R., Althausen, D., Casiccia, C., and Rohwer, E. G.: Contrasting the impact of aerosols at northern and southern midlatitudes on heterogeneous ice formation, Geophysical Research Letters, 38, https://doi.org/https://doi.org/10.1029/2011GL048532, 2011.

Kanitz, T., Ansmann, A., Engelmann, R., and Althausen, D.: North-south cross sections of the vertical aerosol distribution over the Atlantic Ocean from multiwavelength Raman/polarization lidar during Polarstern cruises, Journal of Geophysical Research: Atmospheres, 118, 2643-2655, https://doi.org/10.1002/jgrd.50273, 2013.

KARL: Koldewey Aerosol Raman Lidar, Alfred-Wegener-Institut, https://www.awi.de/en/expedition/stations/awipev-arctic-research-base/ the-koldewey-aerosol-raman-lidar.html, last access: 5 January, 2021.

Khaykin, S., Legras, B., Bucci, S., Sellitto, P., Isaksen, L., Tencé, F., Bekki, S., Bourassa, A., Rieger, L., Zawada, D., Jumelet, J., and GodinBeekmann, S.: The 2019/20 Australian wildfires generated a persistent smoke-charged vortex rising up to $35 \mathrm{~km}$ altitude, Communications Earth \& Environment, 1, 22, https://doi.org/10.1038/s43247-020-00022-5, 2020.

Khaykin, S. M., Godin-Beekmann, S., Hauchecorne, A., Pelon, J., Ravetta, F., and Keckhut, P.: Stratospheric Smoke With Unprecedentedly High Backscatter Observed by Lidars Above Southern France, Geophysical Research Letters, 45, 1639-1646, https://doi.org/10.1002/2017GL076763, 2018.

Klehr, D.: Charakterisierung der Tropopause über Ny-Alesund, Spitzbergen, Bachelor thesis, University Potsdam, https://doi.org/https://epic.awi.de/id/eprint/35063/1/Bachelorarbeit_DavidKlehr.pdf, last access: 5 January, 2021.

Kloss, C., Berthet, G., Sellitto, P., Ploeger, F., Taha, G., Tidiga, M., Eremenko, M., Bossolasco, A., Jégou, F., Renard, J.-B., and Legras, B.: Stratospheric aerosol layer perturbation caused by the 2019 Raikoke and Ulawun eruptions and their radiative forcing, Atmospheric Chemistry and Physics, 21, 535-560, https://doi.org/10.5194/acp-21-535-2021, 2021.

Knust, R.: Polar Research and Supply Vessel POLARSTERN operated by the Alfred-Wegener-Institute, Journal of large-scale research facilities JLSRF, 3, A119, 2017.

Lawrence, Z. D., Perlwitz, J., Butler, A. H., Manney, G. L., Newman, P. A., Lee, S. H., and Nash, E. R.: The Remarkably Strong Arctic Stratospheric Polar Vortex of Winter 2020: Links to Record-Breaking Arctic Oscillation and Ozone Loss, Journal of Geophysical Research: Atmospheres, 125, e2020JD033 271, https://doi.org/https://doi.org/10.1029/2020JD033271, 2020.

Manney, G. L., Livesey, N. J., Santee, M. L., Froidevaux, L., Lambert, A., Lawrence, Z. D., Millán, L. F., Neu, J. L., Read, W. G., Schwartz, M. J., and Fuller, R. A.: Record-Low Arctic Stratospheric Ozone in 2020: MLS Observations of Chemical Processes and Comparisons With Previous Extreme Winters, Geophysical Research Letters, 47, https://doi.org/10.1029/2020GL089063, 2020.

Mattis, I., Siefert, P., Müller, D., Tesche, M., Hiebsch, A., Kanitz, T., Schmidt, J., Finger, F., Wandinger, U., and Ansmann, A.: Volcanic aerosol layers observed with multiwavelength Raman lidar over central Europe in 2008-2009, Journal of Geophysical Research, 115, D00L04, https://doi.org/10.1029/2009JD013472, 2010.

Müller, D., Mattis, I., Wandinger, U., Ansmann, A., Althausen, D., and Stohl, A.: Raman lidar observations of aged Siberian and Canadian forest fire smoke in the free troposphere over Germany in 2003: Microphysical particle characterization, Journal of Geophysical Research: Atmospheres, 110, https://doi.org/https://doi.org/10.1029/2004JD005756, 2005.

Müller, D., Mattis, I., Ansmann, A., Wandinger, U., Ritter, C., and Kaiser, D.: Multiwavelength Raman lidar observations of particle growth during long-range transport of forest-fire smoke in the free troposphere, Geophysical Research Letters, 34, https://doi.org/https://doi.org/10.1029/2006GL027936, 2007. 
MODIS: Combined Dark Target and Deep Blue AOD at 0.55 micron for land and ocean terra MOD08_M3_v6, https://giovanni.gsfc.nasa. gov/, last access: 5 January, 2021.

MOSAiC: homepage, https://mosaic-expedition.org/, last access: 5 January, 2021.

NOAA: Summer 2019 was hottest on record for Northern Hemisphere, https://www.noaa.gov/news/ summer-2019-was-hottest-on-record-for-northern-hemisphere, last access: 5 January, 2021.

Ohneiser, K., Ansmann, A., Baars, H., Seifert, P., Barja, B., Jimenez, C., Radenz, M., Teisseire, A., Floutsi, A., Haarig, M., Foth, A., Chudnovsky, A., Engelmann, R., Zamorano, F., Bühl, J., and Wandinger, U.: Smoke of extreme Australian bushfires observed in the stratosphere over Punta Arenas, Chile, in January 2020: optical thickness, lidar ratios, and depolarization ratios at 355 and 532 nm, Atmospheric Chemistry and Physics, 20, 8003-8015, https://doi.org/10.5194/acp-20-8003-2020, 2020.

Pappalardo, G., Amodeo, A., Apituley, A., Comeron, A., Freudenthaler, V., Linné, H., Ansmann, A., Bösenberg, J., D’Amico, G., Mattis, I., Mona, L., Wandinger, U., Amiridis, V., Alados-Arboledas, L., Nicolae, D., and Wiegner, M.: EARLINET: towards an advanced sustainable European aerosol lidar network, Atmospheric Measurement Techniques, 7, 2389-2409, https://doi.org/10.5194/amt-7-2389-2014, 2014.

Petzold, A., Weinzierl, B., Huntrieser, H., Stohl, A., Real, E., Cozic, J., Fiebig, M., Hendricks, J., Lauer, A., Law, K., Roiger, A., Schlager, H., and Weingartner, E.: Perturbation of the European free troposphere aerosol by North American forest fire plumes during the ICARTT-ITOP experiment in summer 2004, Atmospheric Chemistry and Physics, 7, 5105-5127, https://doi.org/10.5194/acp-7-5105-2007, 2007.

PollyNet: lidar data base, http://polly.rsd.tropos.de/, last access: 5 January, 2021.

Ritter, C., Neuber, R., Schulz, A., Markowicz, K., Stachlewska, I., Lisok, J., Makuch, P., Pakszys, P., Markuszewski, P., Rozwadowska, A., Petelski, T., Zielinski, T., Becagli, S., Traversi, R., Udisti, R., and Gausa, M.: 2014 iAREA campaign on aerosol in Spitsbergen - Part 2: Optical properties from Raman-lidar and in-situ observations at Ny-Ålesund, Atmospheric Environment, 141, 1 - 19, https://doi.org/https://doi.org/10.1016/j.atmosenv.2016.05.053, 2016.

Rolph, G., Stein, A., and Stunder, B.: Real-time Environmental Applications and Display sYstem: READY, Environmental Modelling \& Software, 95, 210-228, https://doi.org/10.1016/j.envsoft.2017.06.025, 2017.

Sakai, T., Uchino, O., Nagai, T., Liley, B., Morino, I., and Fujimoto, T.: Long-term variation of stratospheric aerosols observed with lidars over Tsukuba, Japan, from 1982 and Lauder, New Zealand, from 1992 to 2015, Journal of Geophysical Research: Atmospheres, 121, 10,283-10,293, https://doi.org/10.1002/2016JD025132, 2016.

Smyshlyaev, S. P., Vargin, P. N., Lukyanov, A. N., Tsvetkova, N. D., and Motsakov, M. A.: Dynamical and chemical processes contributing to ozone loss in exceptional Arctic stratosphere winter-spring of 2020, Atmospheric Chemistry and Physics Discussions, 2021, 1-35, https://doi.org/10.5194/acp-2021-11, 2021.

Stein, A. F., Draxler, R. R., Rolph, G. D., Stunder, B. J. B., Cohen, M. D., and Ngan, F.: NOAA's HYSPLIT Atmospheric Transport and Dispersion Modeling System, Bulletin of the American Meteorological Society, 96, 2059-2077, https://doi.org/10.1175/BAMS-D-14$00110.1,2015$.

Stohl, A.: Characteristics of atmospheric transport into the Arctic troposphere, Journal of Geophysical Research, 111, D11306, https://doi.org/10.1029/2005JD006888, 2006.

Taha, G., Loughman, R., Zhu, T., Thomason, L., Kar, J., Rieger, L., and Bourassa, A.: OMPS LP Version 2.0 multi-wavelength aerosol extinction coefficient retrieval algorithm, Atmospheric Measurement Techniques, 14, 1015-1036, https://doi.org/10.5194/amt-14-10152021, https://amt.copernicus.org/articles/14/1015/2021/, 2021. 
Tesche, M., Müller, D., Gross, S., Ansmann, A., Althausen, D., Freudenthaler, V., Weinzierl, B., Veira, A., and Petzold, A.: Optical and microphysical properties of smoke over Cape Verde inferred from multiwavelength lidar measurements, Tellus B: Chemical and Physical Meteorology, 63, 677-694, https://doi.org/10.1111/j.1600-0889.2011.00549.x, 2011.

Torres, O., Bhartia, P. K., Taha, G., Jethva, H., Das, S., Colarco, P., Krotkov, N., Omar, A., and Ahn, C.: Stratospheric Injection of Massive Smoke Plume From Canadian Boreal Fires in 2017 as Seen by DSCOVR-EPIC, CALIOP, and OMPS-LP Observations, Journal of Geophysical Research: Atmospheres, 125, https://doi.org/10.1029/2020JD032579, 2020.

Treffeisen, R. E., Thomason, L. W., Ström, J., Herber, A. B., Burton, S. P., and Yamanouchi, T.: Stratospheric Aerosol and Gas Experiment (SAGE) II and III aerosol extinction measurements in the Arctic middle and upper troposphere, Journal of Geophysical Research, 111, D17 203, https://doi.org/10.1029/2005JD006271, 2006.

Vaughan, G., Wareing, D., and Ricketts, H.: Measurement Report: Lidar measurements of stratospheric aerosol following the Raikoke and Ulawun volcanic eruptions, Atmospheric Chemistry and Physics Discussions, 2020, 1-10, https://doi.org/10.5194/acp-2020-982, 2020.

Veselovskii, I., Kolgotin, A., Griaznov, V., Müller, D., Wandinger, U., and Whiteman, D. N.: Inversion with regularization for the retrieval of tropospheric aerosol parameters from multiwavelength lidar sounding, Appl. Opt., 41, 3685-3699, https://doi.org/10.1364/AO.41.003685, 2002.

Veselovskii, I., Dubovik, O., Kolgotin, A., Korenskiy, M., Whiteman, D. N., Allakhverdiev, K., and Huseyinoglu, F.: Linear estimation of particle bulk parameters from multi-wavelength lidar measurements, Atmospheric Measurement Techniques, 5, 1135-1145, https://doi.org/10.5194/amt-5-1135-2012, 2012.

von der Gathen, P. and Maturilli, M.: Ozone sonde profiles during MOSAiC Leg 1-2-3, https://doi.org/10.1594/PANGAEA.919538, 2020.

Wandinger, U., Ansmann, A., Reichardt, J., and Deshler, T.: Determination of stratospheric aerosol microphysical properties from independent extinction and backscattering measurements with a Raman lidar, Applied Optics, 34, 8315, https://doi.org/10.1364/AO.34.008315, 1995.

Wandinger, U., Müller, D., Böckmann, C., Althausen, D., Matthias, V., Bösenberg, J., Weiß, V., Fiebig, M., Wendisch, M., Stohl, A., and Ansmann, A.: Optical and microphysical characterization of biomass- burning and industrial-pollution aerosols from- multiwavelength lidar and aircraft measurements, Journal of Geophysical Research: Atmospheres, 107, 7-20, https://doi.org/https://doi.org/10.1029/2000JD000202, 2002.

Wendisch, M., Brückner, M., Burrows, J., Crewell, S., Dethloff, K., Ebell, K., Lüpkes, C., Macke, A., Notholt, J., Quaas, J., Rinke, A., and Tegen, I.: Understanding causes and effects of rapid warming in the Arctic, Eos, 98, Advancing Earth and Space Science, https://doi.org/https://doi.org/10.1029/2017EO064803, 2017.

Wendisch, M., Macke, A., Ehrlich, A., Lüpkes, C., Mech, M., Chechin, D., Dethloff, K., Velasco, C. B., Bozem, H., Brückner, M., Clemen, H.-C., Crewell, S., Donth, T., Dupuy, R., Ebell, K., Egerer, U., Engelmann, R., Engler, C., Eppers, O., Gehrmann, M., Gong, X., Gottschalk, M., Gourbeyre, C., Griesche, H., Hartmann, J., Hartmann, M., Heinold, B., Herber, A., Herrmann, H., Heygster, G., Hoor, P., Jafariserajehlou, S., Jäkel, E., Järvinen, E., Jourdan, O., Kästner, U., Kecorius, S., Knudsen, E. M., Köllner, F., Kretzschmar, J., Lelli, L., Leroy, D., Maturilli, M., Mei, L., Mertes, S., Mioche, G., Neuber, R., Nicolaus, M., Nomokonova, T., Notholt, J., Palm, M., van Pinxteren, M., Quaas, J., Richter, P., Ruiz-Donoso, E., Schäfer, M., Schmieder, K., Schnaiter, M., Schneider, J., Schwarzenböck, A., Seifert, P., Shupe, M. D., Siebert, H., Spreen, G., Stapf, J., Stratmann, F., Vogl, T., Welti, A., Wex, H., Wiedensohler, A., Zanatta, M., and Zeppenfeld, S.: The Arctic Cloud Puzzle: Using ACLOUD/PASCAL Multiplatform Observations to Unravel the Role of Clouds and Aerosol Particles in Arctic Amplification, Bulletin of the American Meteorological Society, 100, 841 - 871, https://doi.org/10.1175/BAMS-D-18-0072.1, 2019. 
Wilka, C., Solomon, S., Kinnison, D., and Tarasick, D.: An Arctic Ozone Hole in 2020 If Not For the Montreal Protocol, Atmospheric

Chemistry and Physics Discussions, 2021, 1-16, https://doi.org/10.5194/acp-2020-1297, 2021.

WMO: World Meteorological Organisation, International Meterological Vocabulary, No. 182, ISBN 92-63-02182-1, , 1992.

Wohltmann, I., Gathen, P., Lehmann, R., Maturilli, M., Deckelmann, H., Manney, G. L., Davies, J., Tarasick, D., Jepsen, N., Kivi, R., Lyall, N., and Rex, M.: Near-Complete Local Reduction of Arctic Stratospheric Ozone by Severe Chemical Loss in Spring 2020, Geophysical Research Letters, 47, https://doi.org/10.1029/2020GL089547, 2020.

Yadav, J., Kumar, A., and Mohan, R.: Dramatic decline of Arctic sea ice linked to global warming, Natural Hazards, 103, 2617-2621, https://doi.org/10.1007/s11069-020-04064-y, 2020.

Yang, Y., Zhao, C., Wang, Q., Cong, Z., Yang, X., and Fan, H.: Aerosol Characteristics in the Three Poles of the Earth Observed by CALIPSO, in review, Atmospheric Chemistry and Physics Discussions, 2020, 1-34, https://doi.org/10.5194/acp-2020-1159, 2020.

Yu, P., Toon, O. B., Bardeen, C. G., Zhu, Y., Rosenlof, K. H., Portmann, R. W., Thornberry, T. D., Gao, R.-S., Davis, S. M., Wolf, E. T., de Gouw, J., Peterson, D. A., Fromm, M. D., and Robock, A.: Black carbon lofts wildfire smoke high into the stratosphere to form a persistent plume, Science, 365, 587-590, https://doi.org/10.1126/science.aax1748, 2019.

Zhu, Y., Toon, O. B., Lambert, A., Kinnison, D. E., Brakebusch, M., Bardeen, C. G., Mills, M. J., and English, J. M.: Development of a Polar Stratospheric Cloud Model within the Community Earth System Model using constraints on Type I PSCs from the 2010-2011 Arctic winter, Journal of Advances in Modeling Earth Systems, 7, 551-585, https://doi.org/https://doi.org/10.1002/2015MS000427, 2015.

Zhu, Y., Toon, O. B., Kinnison, D., Harvey, V. L., Mills, M. J., Bardeen, C. G., Pitts, M., Bègue, N., Renard, J.-B., Berthet, G., and Jégou, F.: Stratospheric Aerosols, Polar Stratospheric Clouds, and Polar Ozone Depletion After the Mount Calbuco Eruption in 2015, Journal of Geophysical Research: Atmospheres, 123, 12,308-12,331, https://doi.org/https://doi.org/10.1029/2018JD028974, 2018. 
Table 1. Optical and microphysical properties of the polar wildfire smoke layer in the autumn of 2019. Layer mean values of the particle backscatter coefficient $\beta$, extinction coefficient $\sigma$, lidar ratio $S$, and backscatter, extinction and lidar-ratio-related Ångström exponents $A_{\beta}$, $A_{\sigma}$, and $A_{\mathrm{S}}$, respectively, are given in the upper part. Indices indicate wavelength in $\mathrm{nm}$ and wavelength spectrum. The lower block contains the retrieved particle number concentration (particles with radius $>50 \mathrm{~nm}$ ), mean and effective particle radius $r_{\text {mean }}$ and $r_{\text {eff }}$, volume $(V)$, mass $(m)$, and surface area $(s)$ concentration, real $\left(n_{\text {real }}\right)$ and imaginary part $\left(n_{\text {imag }}\right)$ of the refractive index, and single scattering albedo SSA. Uncertainties are of the order of $10 \%(\beta), 15 \%(\sigma), 20 \%(S, A), 100 \%(N), 20 \%(V, m, s), \pm 0.05\left(n_{\text {real }}\right)$, up to $50 \%\left(n_{\text {imag }}\right)$, and 0.05 (SSA).

\begin{tabular}{|c|c|c|c|}
\hline Parameter & 13 Oct 2019 & 25 Oct 2019 & 7 Nov 2019 \\
\hline Height, base to top $[\mathrm{km}]$ & $4.5-15$ & $5.5-16$ & $5.5-14$ \\
\hline$\beta_{355}\left[\mathrm{Mm}^{-1} \mathrm{sr}^{-1}\right]$ & 0.250 & 0.233 & 0.250 \\
\hline$\beta_{532}\left[\mathrm{Mm}^{-1} \mathrm{sr}^{-1}\right]$ & 0.116 & 0.117 & 0.124 \\
\hline$\beta_{1064}\left[\mathrm{Mm}^{-1} \mathrm{sr}^{-1}\right]$ & 0.037 & 0.039 & 0.039 \\
\hline$\sigma_{355}\left[\mathrm{Mm}^{-1}\right]$ & 13.8 & 11.2 & 11.3 \\
\hline$\sigma_{532}\left[\mathrm{Mm}^{-1}\right]$ & 10.4 & 8.2 & 8.7 \\
\hline$S_{355}[\mathrm{sr}]$ & 55 & 48 & 45 \\
\hline$S_{532}[\mathrm{sr}]$ & 90 & 70 & 70 \\
\hline$A_{\beta, 355,532}$ & 1.88 & 1.71 & 1.72 \\
\hline$A_{\beta, 532,1064}$ & 1.66 & 1.59 & 1.68 \\
\hline$A_{\sigma, 355,532}$ & 0.68 & 0.78 & 0.63 \\
\hline$A_{\mathrm{S}, 355,532}$ & -1.22 & -0.93 & -1.09 \\
\hline$N(r>50 \mathrm{~nm})\left[\mathrm{cm}^{-3}\right]$ & 42 & 55 & 42 \\
\hline$r_{\text {mean }}[\mu \mathrm{m}]$ & 0.18 & 0.15 & 0.17 \\
\hline$r_{\text {eff }}[\mu \mathrm{m}]$ & 0.22 & 0.20 & 0.22 \\
\hline$V\left[\mu \mathrm{m}^{3} \mathrm{~cm}^{-3}\right]$ & 1.2 & 0.98 & 1.0 \\
\hline$m\left[\mu \mathrm{g} \mathrm{m}^{-3}\right]$ & 1.38 & 1.13 & 1.15 \\
\hline$s\left[\mu \mathrm{m}^{2} \mathrm{~cm}^{-3}\right]$ & 16.0 & 14.8 & 14.0 \\
\hline$n_{\text {real }}$ & 1.49 & 1.50 & 1.50 \\
\hline$n_{\text {imag }}$ & 0.010 & 0.007 & 0.007 \\
\hline SSA, $355 \mathrm{~nm}$ & 0.948 & 0.961 & 0.962 \\
\hline SSA, $532 \mathrm{~nm}$ & 0.956 & 0.967 & 0.969 \\
\hline SSA, 1064 nm & 0.930 & 0.950 & 0.954 \\
\hline
\end{tabular}


Table 2. Mean values and standard deviations of smoke optical properties computed from the time series in Fig. 12. 151 daily observations from the beginning of October 2019 to mid of March 2020 are considered. $\delta_{\mathrm{p}}$ denotes the particle linear depolarization ratio (PLDR). In the case of the lidar ratio $S$, we checked all daily profiles and subjectively selected only cases with clear profile information, not corrupted by a too high noise level so that the profile was strongly fluctuating. 46 days ( $355 \mathrm{~nm}$ lidar ratio) and 36 days (532 nm lidar ratio) are considered. The Ångström exponents for the lidar ratio and the extinction coefficient are calculated from the mean values of $S_{355}$ and $S_{532}$ in Fig. 12 and the mean values of $\sigma_{355}$ and $\sigma_{532}$ in Fig. $9 \mathrm{c}$.

\begin{tabular}{ll}
\hline Parameter & Mean $\pm \mathrm{SD}$ \\
\hline$\delta_{\mathrm{p}, 355}$ & $0.02 \pm 0.0086$ \\
$\delta_{\mathrm{p}, 532}$ & $0.0152 \pm 0.0049$ \\
$S_{355}[\mathrm{sr}]$ & $54.5 \pm 5.5 \mathrm{sr}$ \\
$S_{532}[\mathrm{sr}]$ & $85.3 \pm 10.4 \mathrm{sr}$ \\
$A_{\beta, 355,532}$ & $1.7 \pm 0.7$ \\
$A_{\beta, 532,1064}$ & $2.56 \pm 0.51$ \\
$A_{\beta, 355,532}$ & $1.62 \pm 0.32$ \\
$A_{\sigma, 355,532}$ & 0.62 \\
$A_{\mathrm{S}, 355,532}$ & -1.07 \\
\hline
\end{tabular}



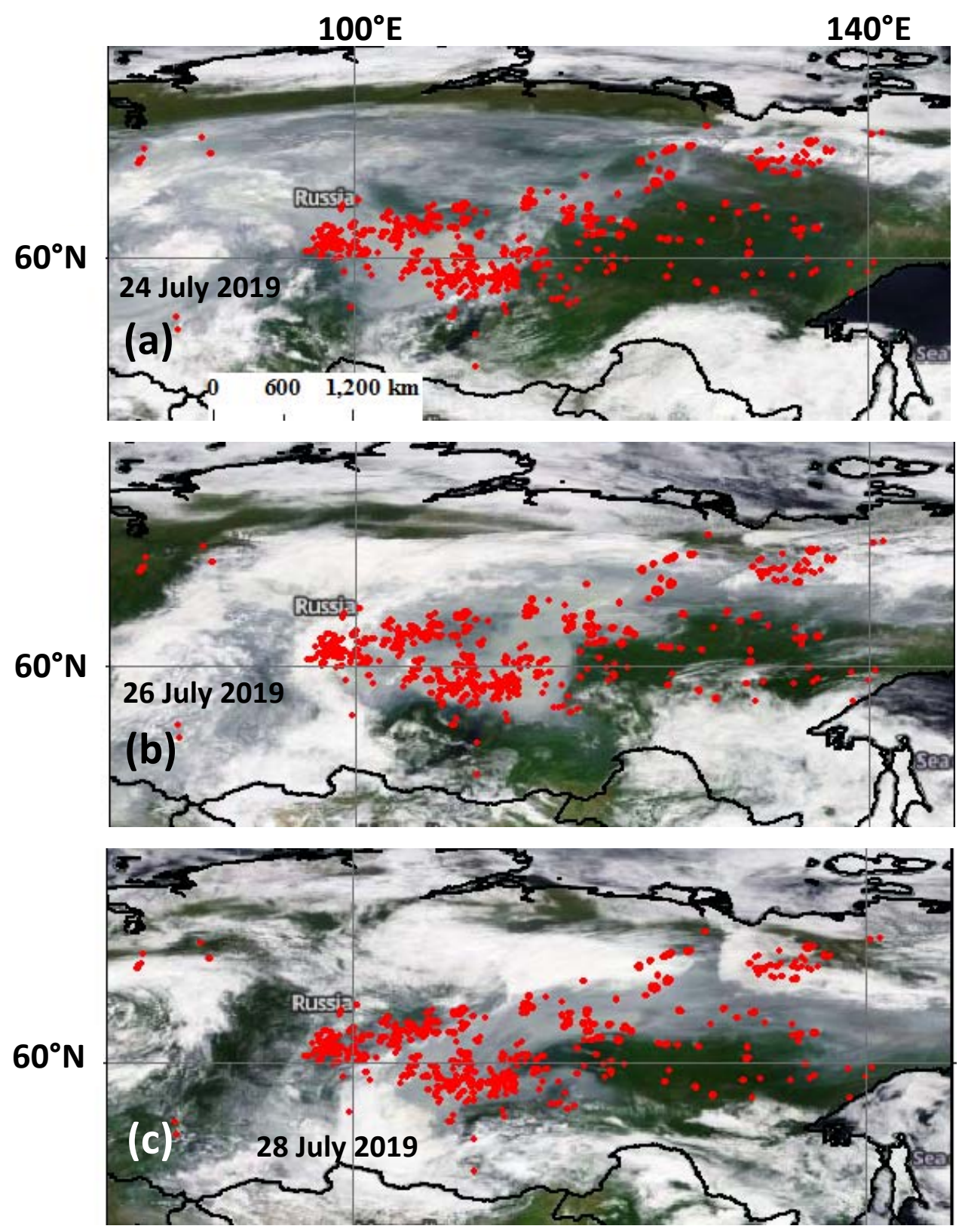

Figure 1. Extended dense fields of wildfire smoke (grey areas) north of Lake Baikal originating from extraordinarily strong wildfires in eastern Siberia (MODIS, last access: 5 January, 2021), (a) MODIS overpass on 24 July 2019, (b) on 26 July 2019 , and (c) on 28 July 2019. White areas indicate cloud layers. Fires detected at the three days are given as red dots (FIRMS, last access: 5 January, 2021). 


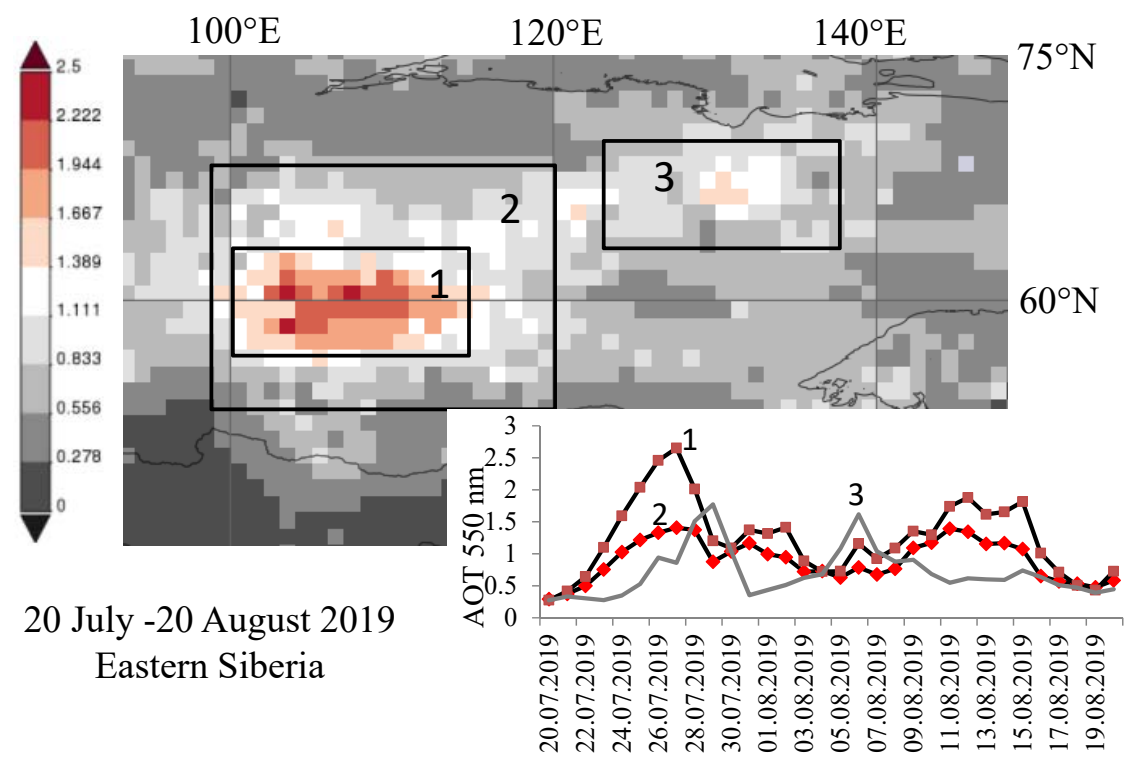

Figure 2. Monthly mean AOT (550 nm, 20 July - 20 August 2019) north (boxes 1 and 2) and northeast (box 3) of Lake Baikal, Russia, and time series of daily mean AOT (mean AOT of boxes 1, 2, and 3) (MODIS, last access: 5 January, 2021).

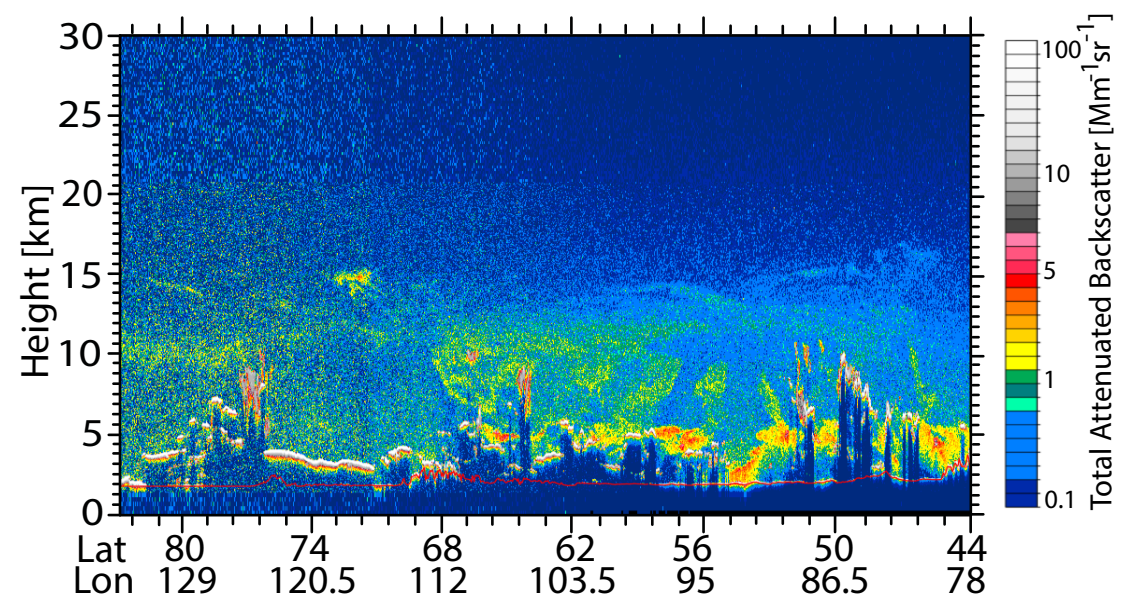

Figure 3. CALIPSO lidar measurement (height-latitude/longitude display of $532 \mathrm{~nm}$ attenuated aerosol backscatter) of wildfire smoke over eastern Siberia during an overpass over an extended forest fire area $\left(55^{\circ}-68^{\circ} \mathrm{N}, 93^{\circ}-112^{\circ} \mathrm{E}\right)$ on 26 July 2016, 20:59-21:08 UTC (CALIOP, last access: 5 January, 2021). Thick smoke plumes (red and yellow) occurred below $5 \mathrm{~km}$ height. Ascending smoke plumes (mostly in green) are visible up to the tropopause at 10-11 km height as well as in the lower stratosphere up to $15 \mathrm{~km}$, partly mixed with volcanic aerosol (bluish colors at heights above $10 \mathrm{~km}$ ) probably originating from the Raikoke volcanic eruption. 


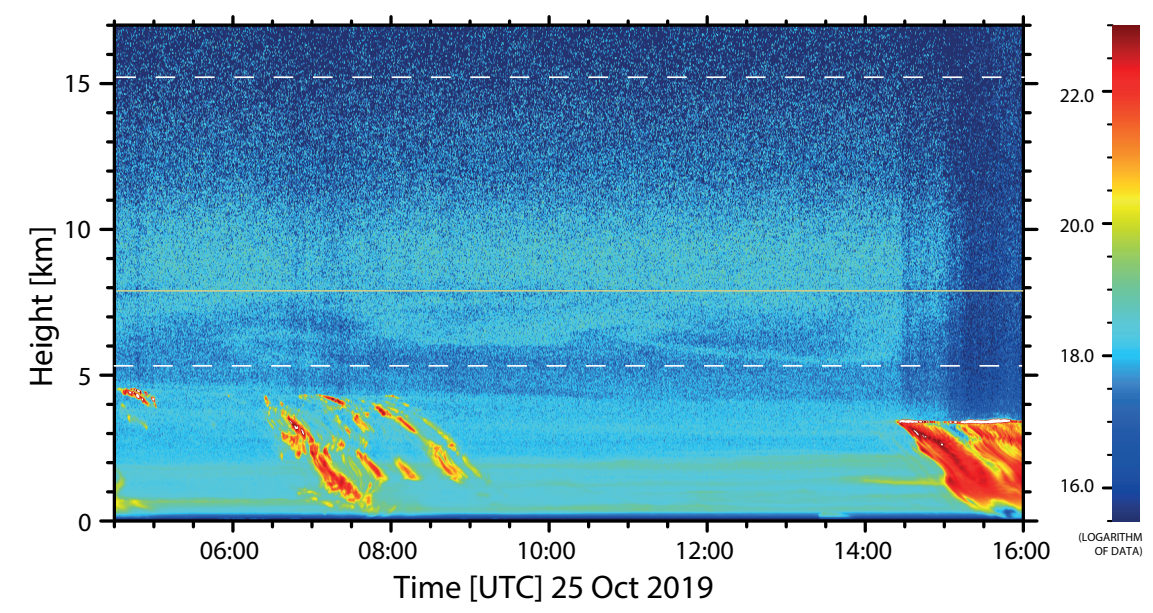

Figure 4. The wildfire smoke layer over RV Polarstern at $85.4^{\circ} \mathrm{N}, 128.0^{\circ} \mathrm{E}$ on 25 October 2019, 4:30-16:30 UTC. The tropopause height according to the Polarstern radiosonde (launched at 12:00 UTC) is given as an orange solid line and the base and top height of the smoke layer are indicated by white dashed lines. Further haze layers and embedded cirrus clouds (virga in yellow to red) are visible at heights below $5 \mathrm{~km}$. The uncalibrated attenuated backscatter coefficient at $1064 \mathrm{~nm}$ (in arbitrary units) is shown.

\section{0-Hour Backward Trajectories ending 12 UTC on 25 Oct 2019 at RV Polarstern}

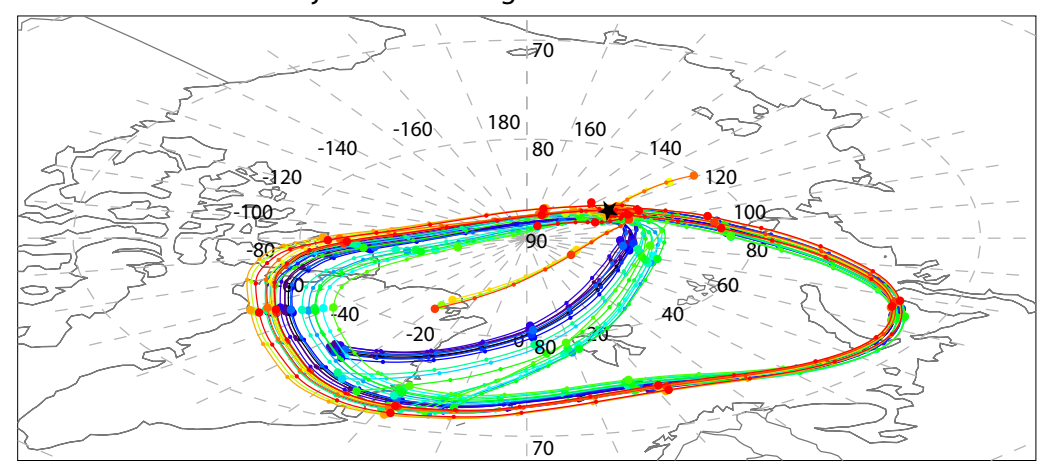

Figure 5. The 10-d ensemble backward trajectories arriving at RV Polarstern (black star) on 25 October 2019, 1200 UTC, at $10 \mathrm{~km}$ height (HYSPLIT, last access: 5 January, 2021; Stein et al., 2015; Rolph et al., 2017). Thin and thick symbols indicate 6-hour and 24-hour time steps, respectively. 


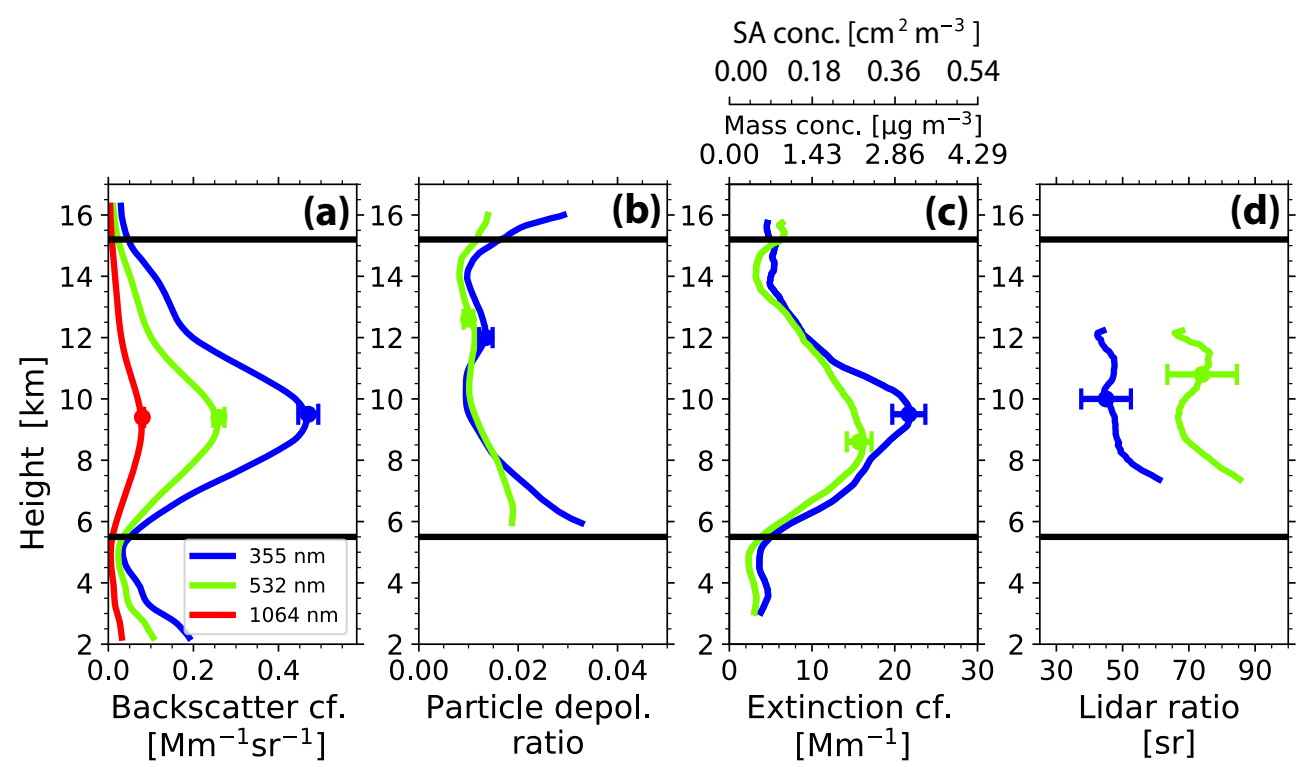

Figure 6. Profiles of optical properties (4.5 h mean values) of the wildfire smoke layer on 25 October 2019, 09:30-14:00 UTC (cirrusfree period, Fig. 4). Base and top heights of the smoke layer are indicated by black horizontal lines. (a) Particle backscatter coefficient at three wavelengths, (b) particle linear depolarization ratio at 355 and $532 \mathrm{~nm}$, (c) smoke extinction coefficient at 355 and $532 \mathrm{~nm}$, and d) respective smoke extinction-to-backscatter ratio (lidar ratio) are shown. Vertical resolution is about $500 \mathrm{~m}$ (backscatter, depolarization ratio), $2000 \mathrm{~m}$ (extinction coefficient), and $2400 \mathrm{~m}$ (lidar ratio). Mass concentration and surface area concentration (obtained from conversion of the extinction coefficients) are given in addition (upper x-axix in c). Error bars indicate the estimated uncertainties around layer center. Depolarization ratios and extinction coefficients close to and around the layer boundaries have to be interpreted with caution. 

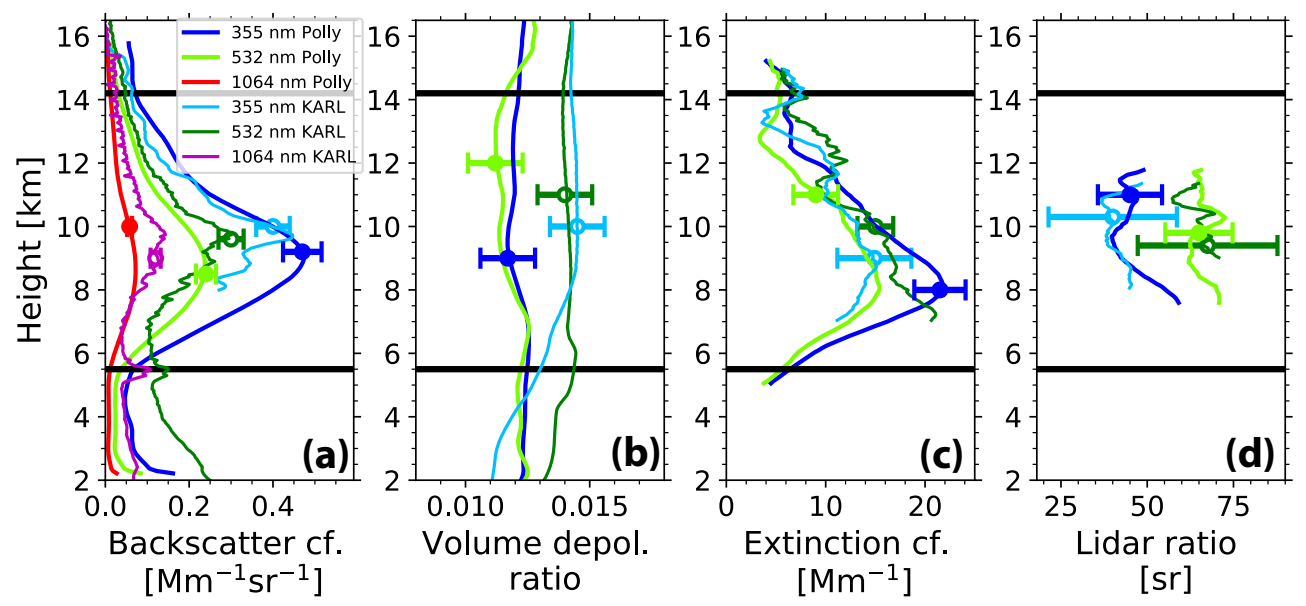

Figure 7. Same as in Fig. 6, except for 7 November 2019 (20:25-23:35 UTC, 85. $\left.9^{\circ} \mathrm{N}, 116.8^{\circ} \mathrm{E}\right)$. KARL (AWI lidar at Ny-Ålesund, Svalbard, Norway, $78.9^{\circ} \mathrm{N}, 11.9^{\circ} \mathrm{E}$ ) observations from 4 Nov 2019 are shown for comparison (open symbols, thin lines). $2400 \mathrm{~m}$ vertical signal smoothing is applied. Note that (b) shows the volume depolarization ratio instead of the particle linear depolarization ratio as in Fig. 6. Good agreement between the different observation was found. Tropopause over Polarstern was at $7.6 \mathrm{~km}$ height.

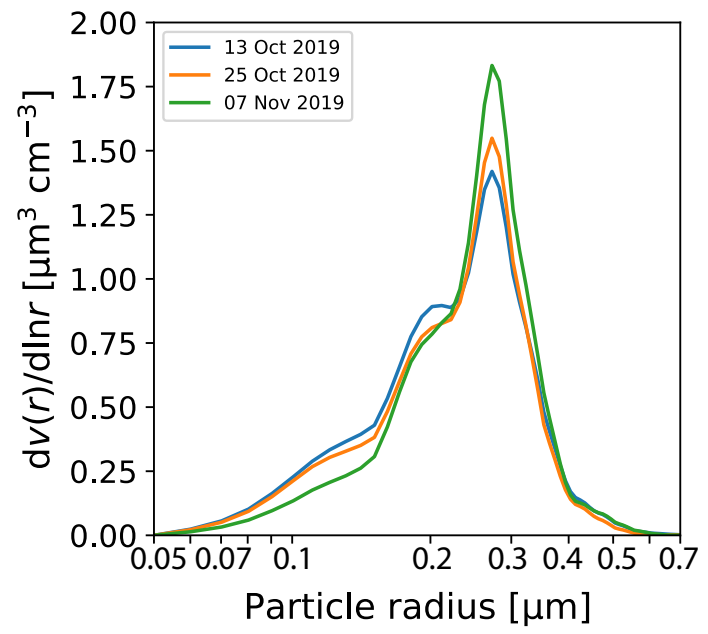

Figure 8. Size distributions of the stratospheric smoke particles retrieved from the multiwavelength lidar observations on 13 and 25 October and 7 November 2019. A narrow accumulation mode with particle sizes (diameters) from 400 to $1000 \mathrm{~nm}$ and a weak Aitken mode to the left is typical for aged wildfire smoke particles. All size distributions are normalized so that the integral over each distribution is one. 


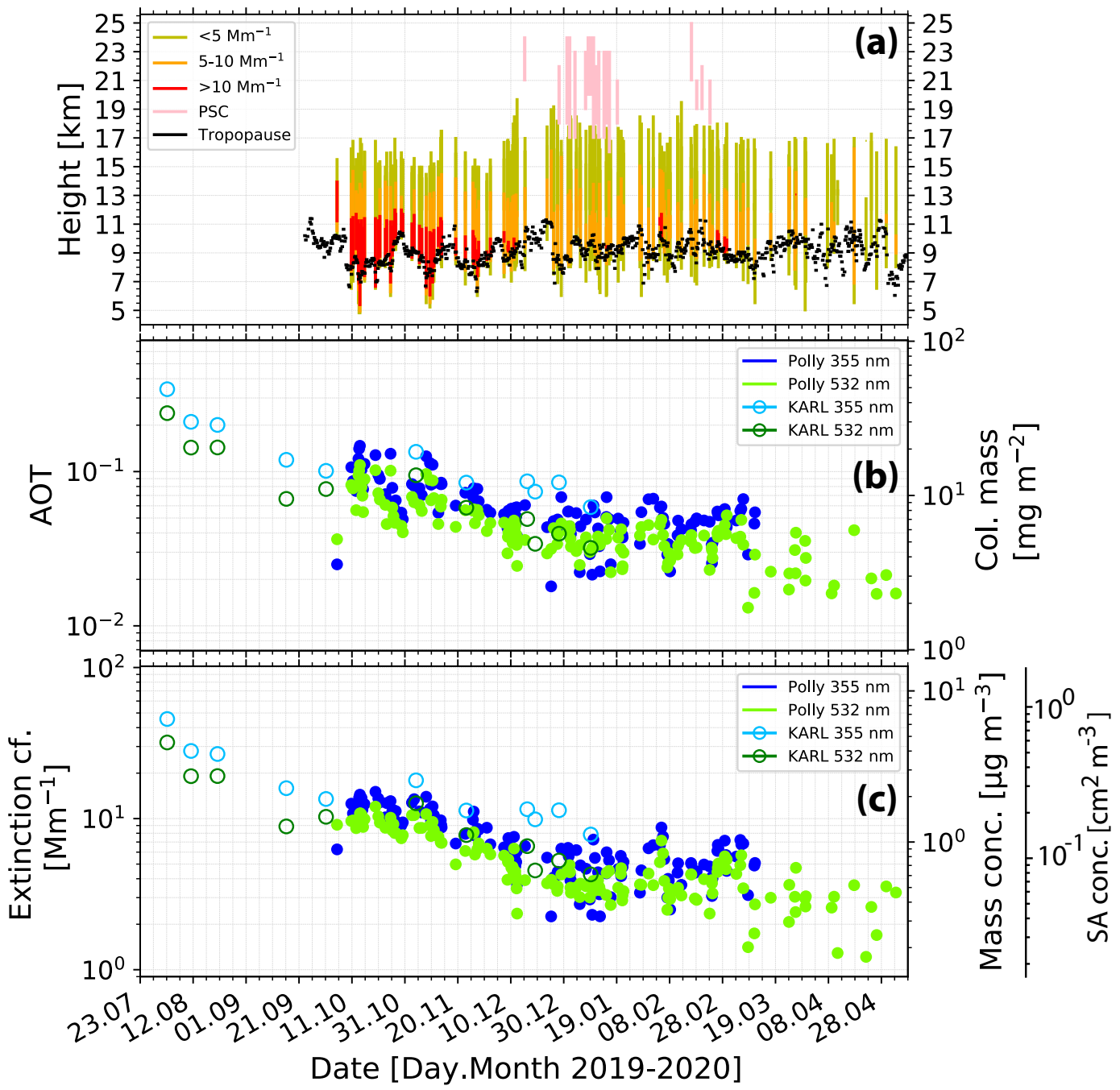

Figure 9. (a) Overview of Polly observations of UTLS smoke layers (colored bars from bottom to top, one bar per day) from 23 July 2019 to 8 May 2020. Observational gaps between bars are caused by opaque low level clouds and fog. The colors in each bar indicate segments with different extinction coefficient levels ( $<5 \mathrm{Mm}^{-1}, 5-10 \mathrm{Mm}^{-1}$, and $>10 \mathrm{Mm}^{-1}$, see legend in the panel). Furthermore, the tropopause is indicated as small black bars, and PSCs layers are shown as pink vertical lines. (b) Smoke layer AOT (KARL, open symbols, Polly, closed symbols) at $355 \mathrm{~nm}$ and $532 \mathrm{~nm}$, calculated from the profiles of the backscatter coefficients multiplied by a lidar ratio of $55 \mathrm{sr}$ and $85 \mathrm{sr}$, respectively. Column mass concentrations are indicated as well (right y-axis). (c) Layer mean 355 and 532 nm particle extinction coefficient (i.e., AOT in panel b divided by layer depth in panel a), and respective mass and surface area concentrations (right y-axis). For comparison, background AOT and extinction levels (532 nm) are of the order of 0.001-0.002 and 0.1-0.2 $\mathrm{Mm}^{-1}$, respectively (Baars et al., 2019). 


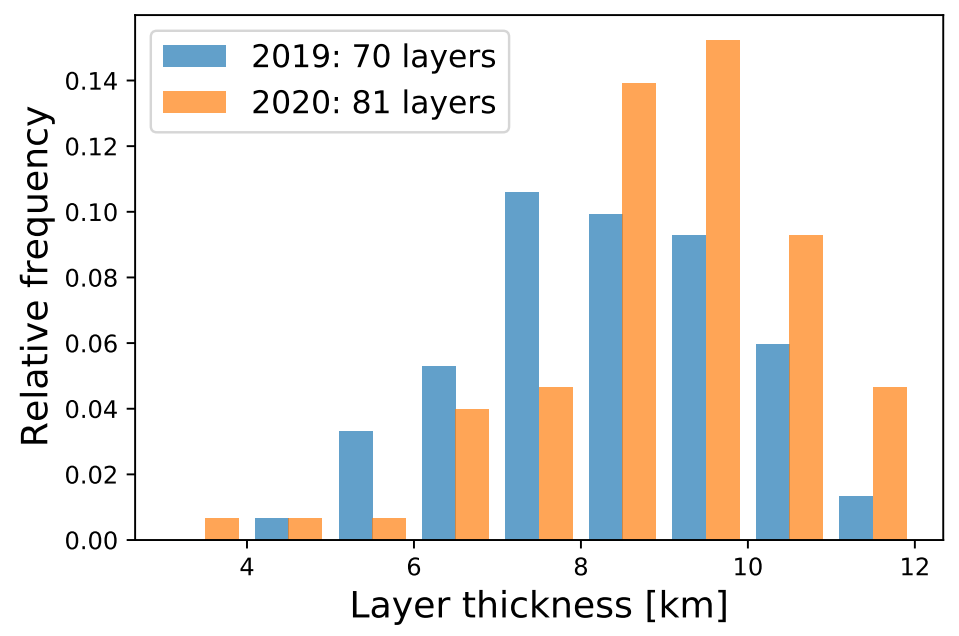

Figure 10. Frequency of occurrence of smoke layer depth. 151 days are considered.

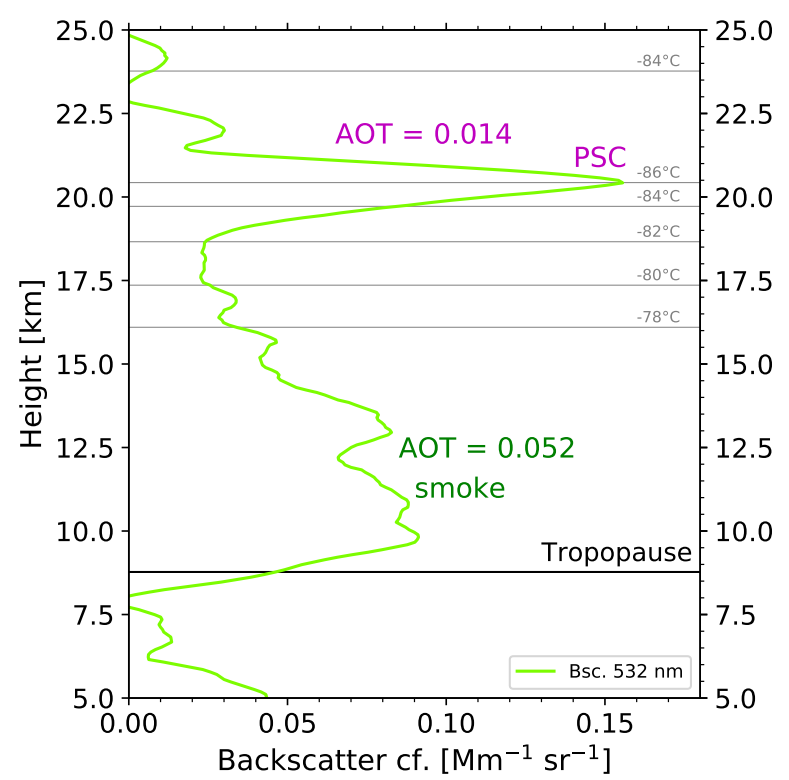

Figure 11. Polar stratospheric cloud (PSC) from 18-22.5 km height on top of the smoke layer on 15 January 2020, 22:30-23:30 UTC. The $532 \mathrm{~nm}$ particle backscatter coefficient is shown and the AOT values for the smoke (computed from the backscatter values multiplied by a lidar ratio of $85 \mathrm{sr}$ ) and of the PSC layer (computed from the backscatter values multiplied by a lidar ratio of $50 \mathrm{sr}$ ) are given as numbers. Horizontal gray lines show different temperature levels. Tropopause was at $8.8 \mathrm{~km}$ height. 


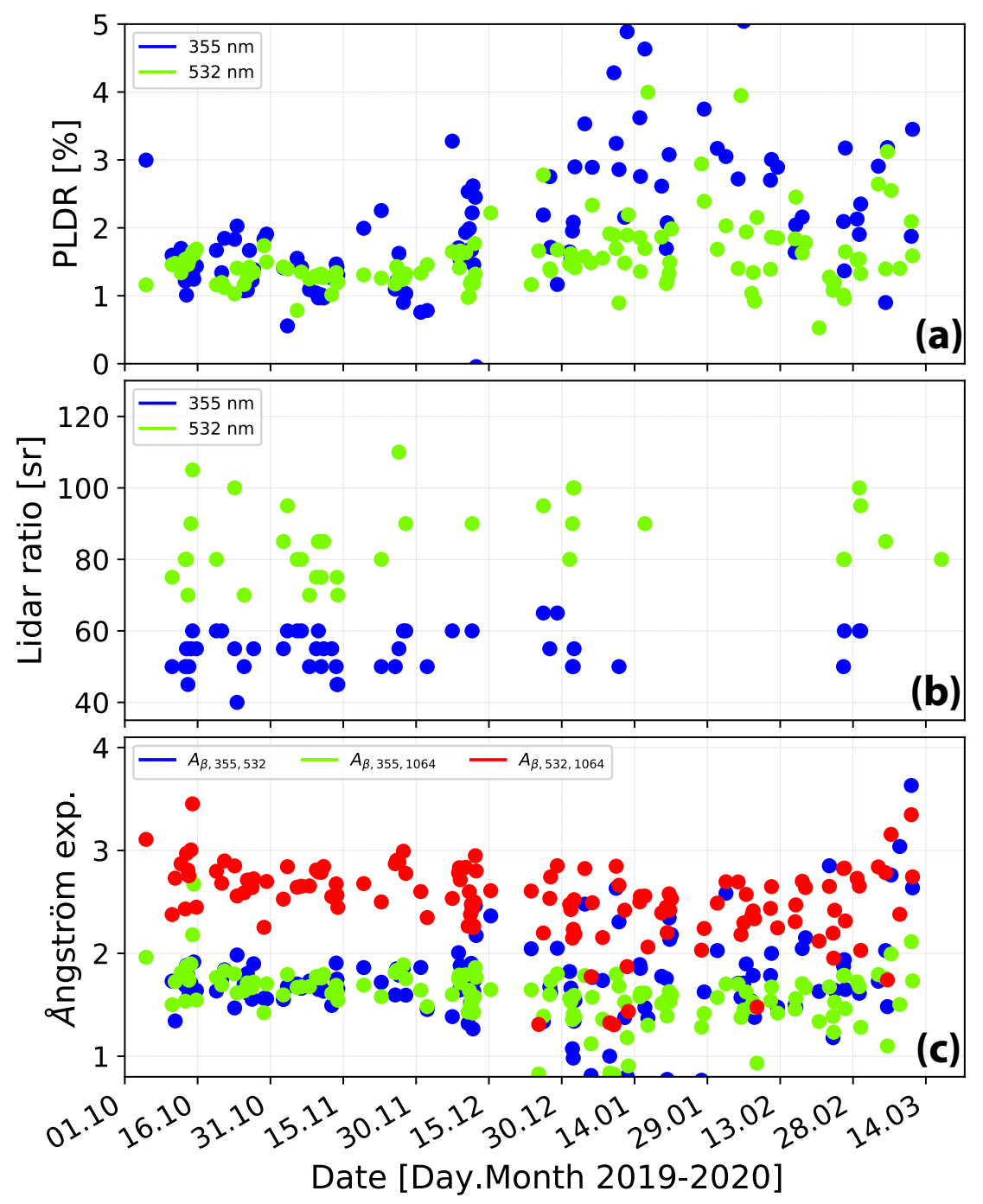

Figure 12. (a) Overview of smoke optical properties in terms of (a) particle linear depolarization ratio (PLDR), (b) extinction-to-backscatter ratio (lidar ratio), and (c) backscatter-related Ångström exponent defined as $\ln \left(\beta_{i} / \beta_{j}\right) / \ln \left(\lambda_{j} / \lambda_{i}\right)$ with backscatter coefficient $\beta_{i}$ for laser wavelength $\lambda_{i}$. All results are derived from Polly observations within the smoke layer. The considered time period spans from 1 October 2019 to 22 March 2020. 


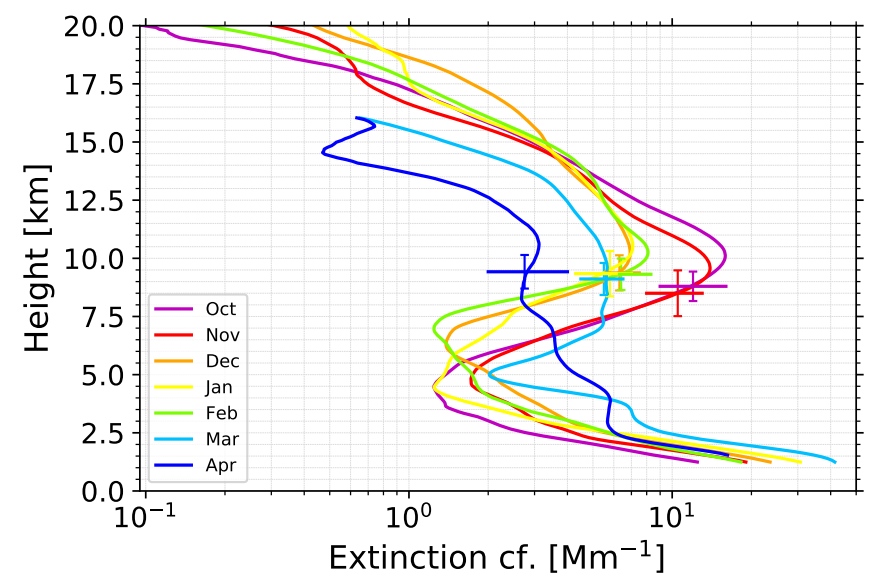

Figure 13. Monthly mean profiles of the $532 \mathrm{~nm}$ particle extinction coefficient. The monthly mean tropopause (with standard deviation bars) is indicated by short horizontal bars. Very constant aerosol conditions were observed during the central winter months (December to February).

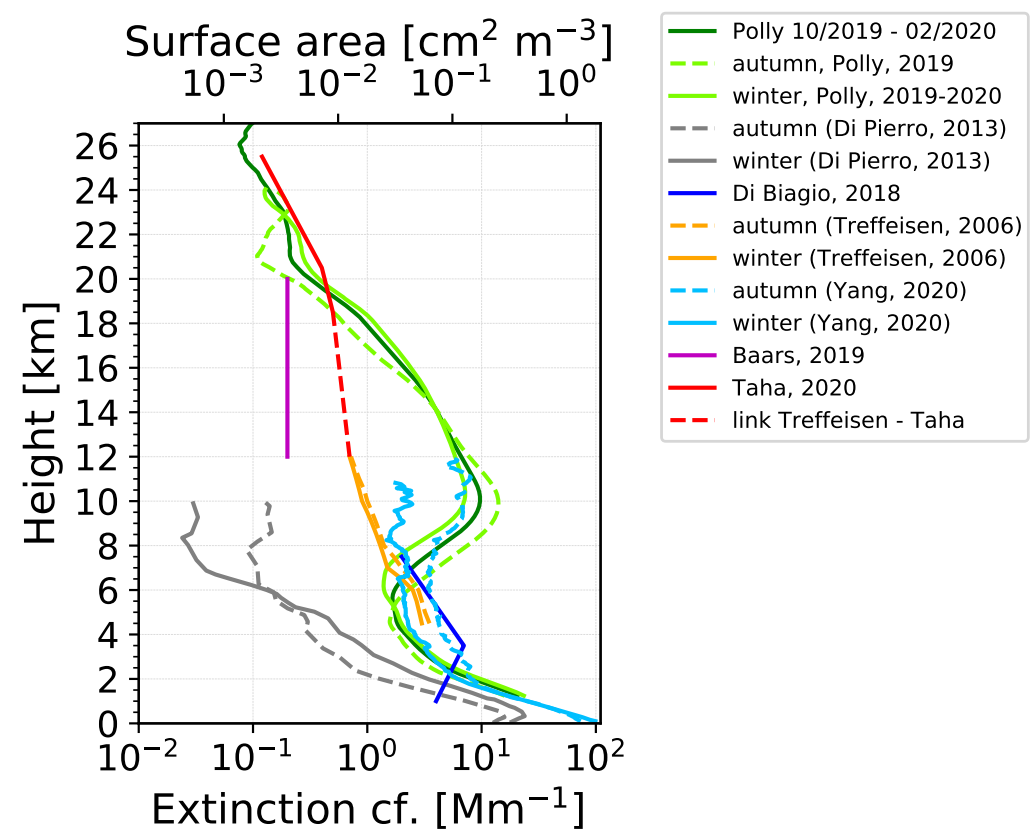

Figure 14. Comparison of seasonally averaged particle extinction coefficient profiles (autumn: October and November, winter: December to February), measured with the Polarstern lidar, with profile observations found in the literature (see list to the right of the figure). The surface area concentration (upper y-axis) is related to the MOSAiC smoke extinction profiles (by applying surface-area-to-extinction conversion factors for smoke). More details are given in the text. 


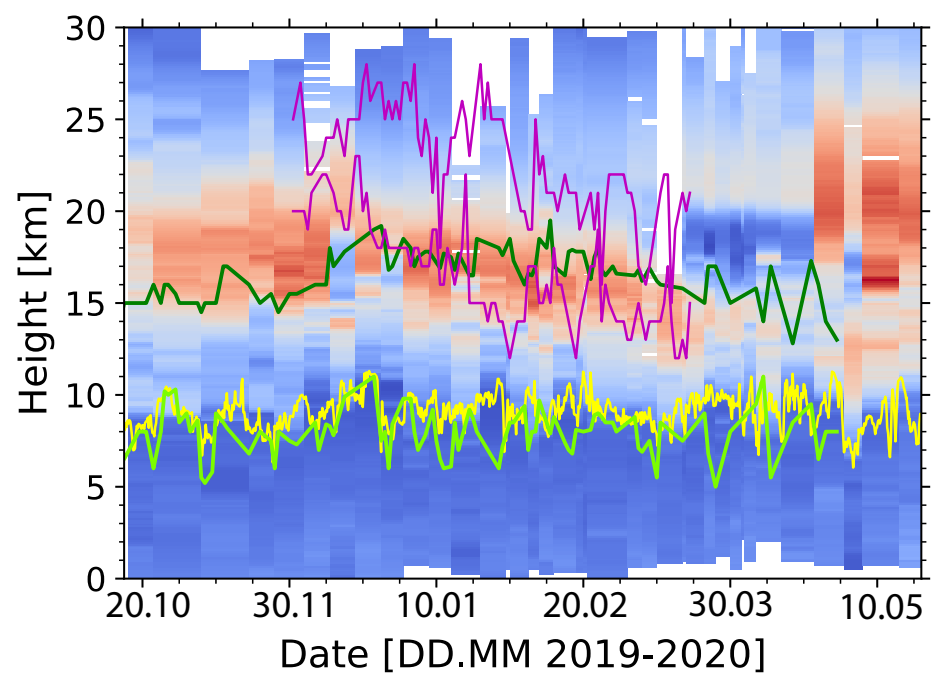

Figure 15. Height-time display of the ozone partial pressure observed with ozonesondes launched at Polarstern. The PSC height range (according to daily CALIPSO lidar observations between 60 and $80^{\circ} \mathrm{N}$ ) is indicated by pink lines. The smoke layer from base (green) to top (dark green) as observed with the MOSAiC lidar over Polarstern (at $>85^{\circ} \mathrm{N}$ ) is indicated as well. The yellow line shows the tropopause.

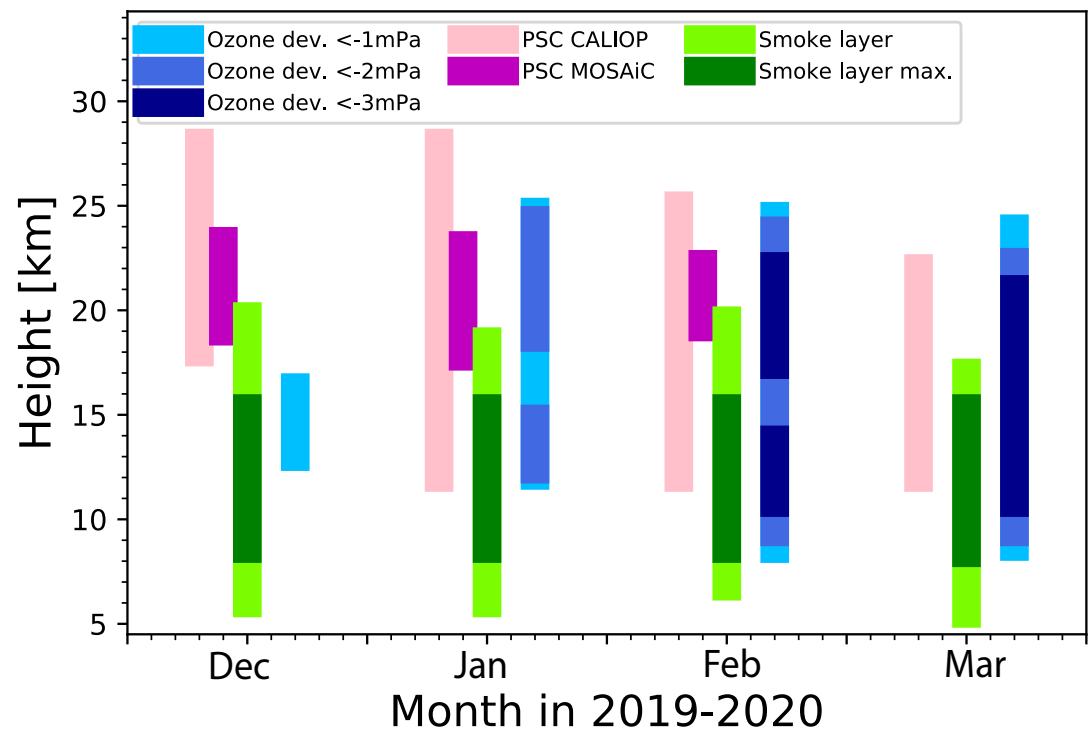

Figure 16. Height range with negative ozone deviation of 1-2 $\mathrm{mPa}$ (light blue), 2-3 $\mathrm{mPa}$ (blue) and $>3 \mathrm{mPa}$ (dark blue) from the longterm climatological monthly mean (2003-2019) at $90^{\circ} \mathrm{N}$ (as shown in Fig. 6c1-c4 in (Inness et al., 2020)). The light and dark pink vertical bars show the height ranges in which PSCs were detected with the CALIPSO lidar between 60 and $80^{\circ} \mathrm{N}$ and with the Polarstern lidar (at $>85^{\circ} \mathrm{N}$ ), respectively. The green bars indicate the smoke layer from base to top, dark green indicates the central range with particle extinction coefficients $>3 \mathrm{Mm}^{-1}$. 